
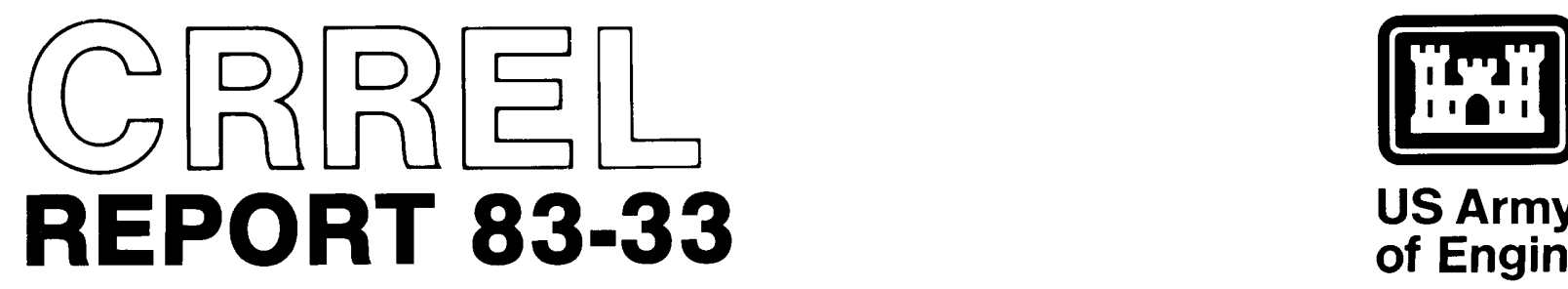

US Army Corps of Engineers

Cold Regions Research \& Engineering Laboratory

Thermodynamic model of creep at constant stresses and constant strain rates

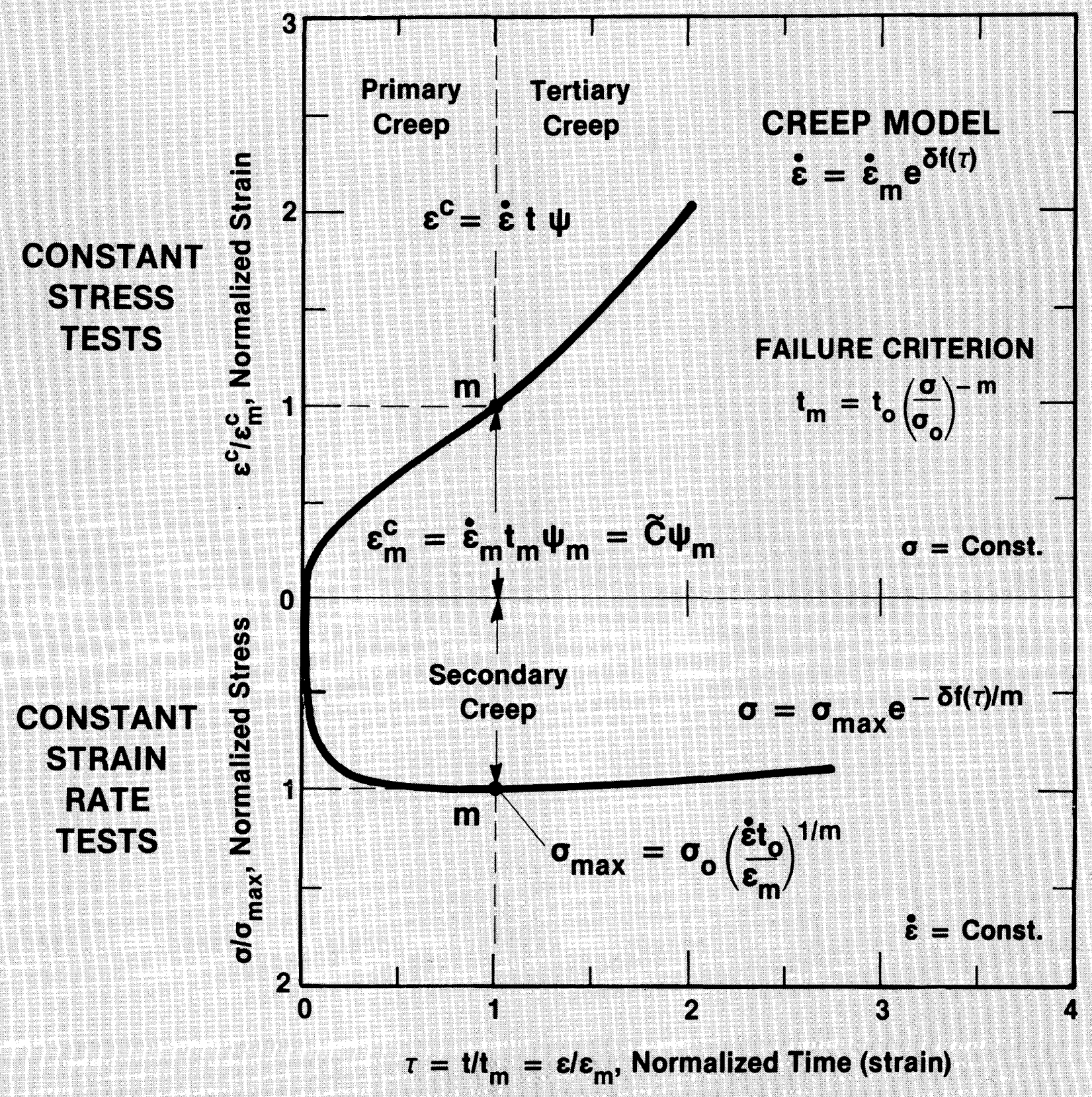




\section{CRREL Report 83-33}

December 1983

\section{Thermodynamic model of creep at constant stresses and constant strain rates}

Anatoly M. Fish 


\begin{tabular}{|c|c|}
\hline REPORT DOCUMENTATION PAGE & $\begin{array}{l}\text { READ INSTRUCTIONS } \\
\text { BEFORE COMPLETING FORM }\end{array}$ \\
\hline $\begin{array}{l}\text { 1. REPORT NUMBER } \\
\text { CRREL Report 83-33 }\end{array}$ & 3. RECIPIENT'S CATALOG NUMBER \\
\hline $\begin{array}{l}\text { 4. TITLE (and Subtitie) } \\
\text { THERMODYNAMIC MODEL OF CREEP AT CONSTANT } \\
\text { STRESSES AND CONSTANT STRAIN RATES }\end{array}$ & 6. PERFORMING ORG. REPORT NUMBER \\
\hline $\begin{array}{l}\text { 7. AUTHOR(s) } \\
\text { Anatoly M. Fish }\end{array}$ & 8. CONTRACT OR GRANT NUMBER( $(s)$ \\
\hline $\begin{array}{l}\text { 9. PERFORMING ORGANIZATION NAME AND ADDRESS } \\
\text { U. S. Army Cold Regions Research and Engineering Laboratory } \\
\text { Hanover, New Hampshire } 03755\end{array}$ & $\begin{array}{l}\text { 10. PROGRAM ELEMENT, PROJECT, TASK } \\
\text { AREA \& WORK UNIT NUMBERS } \\
\text { Project 4A762730AT42, Task D, Work } \\
\text { Unit } 006\end{array}$ \\
\hline \multirow{2}{*}{$\begin{array}{l}\text { 11. CONTROLLING OFFICE NAME AND ADDRESS } \\
\text { Office of the Chief of Engineers } \\
\text { Washington, DC } 20314\end{array}$} & $\begin{array}{l}\text { 12. REPORT DATE } \\
\text { December } 1983\end{array}$ \\
\hline & $\begin{array}{l}\text { 13. NUMBER OF PAGES } \\
25\end{array}$ \\
\hline \multirow[t]{2}{*}{ 14. MONITORING AGENCY NAME \& ADDRESS(If different from Controlling Office) } & $\begin{array}{l}\text { 15. SECURITY CLASS. (of this report) } \\
\text { Unclassified }\end{array}$ \\
\hline & $\begin{array}{l}\text { 15e. DECLASSIFICATION/DOWNGRADING } \\
\text { SCHEDULE }\end{array}$ \\
\hline
\end{tabular}

Approved for p'sblic release; distribution unlimited.

17. DISTRIBUTION STATEMENT (of the abstract ontered in Block 20, if different from Report)

18. SUPPLEMENTARY NOTES

19. KEY WORDS (Continue on reverso side if necessary and identify by block number)

Activation energy Failure criteria Stress-strain

Constitutive equation

Frozen soils

Creep model

Ice

Ductile materials

Soils

Entropy

Strength

20. AGSTAACT (Continue an reveros sidie if necestary and identify by block number)

A thermodynamic model has been developed that for the first time describes the entire creep process, including primary, secondary, and tertiary creep, and failure for both constant stress (CS) tests ( $\sigma=$ const.) and constant strain rate (CSR) tests $(\dot{\epsilon}=$ const.), in the form of a unified constitutive equation and unified failure criteria. Deformation and failure are considered as a single thermoactivated process in which the dominant role belongs to the change of entropy. Failure occurs when the entropy change is zero. At that moment the strain rates in CS tests reach the minima and stress in CSR tests reaches the maximum (peak) values. Families of creep ( $\epsilon$ vs $t$ ) and stress-strain ( $\sigma$ vs $\epsilon$ ) curves, obtained from uniaxial compression CS and CSR tests of frozen soil, respectively (both presented in dimensionless coordinates), are plotted as straight lines and are superposed, confirming the unity of the deformation and failure process and the validity of the 
SECURITY CLASSIFICATION OF THIS PAGE(Thon Data Entored)

20. Abstract (cont'd).

model. A method is developed for determining the parameters of the model, so that creep deformation and the stress-

strain relationship of ductile materials such as soils can be predicted based upon information obtained from either type of test. 


\section{PREFACE}

This report was prepared by Anatoly M. Fish, Research Civil Engineer, of the Geotechnical Research Branch, Experimental Engineering Division, U.S. Army Cold Regions Research and Engineering Laboratory. Recent funding for this research was provided by the Department of Army Project No. 4A762730AT42, Design, Construction and Operations Technology for Cold Regions; Task D, Cold Regions Base Support; Work Unit 006, Design Criteria for Foundations in Permafrost Areas.

These studies were started in 1965 to 1977 at the Institute of Foundations and Underground Structures, Moscow, U.S.S.R. under supervision of Dr. S.S. Vialov, Deputy Director, and Dr. Iu.K. Zaretskii, the author's scientific advisor on his thesis (1976) for Candidate of Sciences Degree, and major elements of this model were presented there. The author acknowledges the attention to these studies of Drs. V.V. Bogorodskii of the Arctic and Antarctic Institute and V.R. Regel, Deputy Director of the Institute of Solid State Physics, Leningrad.

From 1978 to 1980, the author continued these studies while a Research Associate in the Department of Civil Engineering, Massachusetts Institute of Technology, Cambridge, Massachusetts, on special assignment to the U.S. Army Cold Regions Research and Engineering Laboratory. Funding was provided by the U.S. Army Research Office, Durham, North Carolina.

This report was technically reviewed by Dr. Andrew Assur, Francis H. Sayles, and Austin Kovacs of the U.S. Army Cold Regions Research and Engineering Laboratory.

The author is indebted to Zhu Yuanlin of the Lanzhou Institute of Glaciology and Cryopedology, Academia Sinica, People's Republic of China, and D.L. Carbee of the U.S. Army Cold Regions Research and Engineering Laboratory who provided the test data of soils.

Acknowledgment is due to Andrew Assur, William F. Quinn, and Albert F. Wuori for their longterm support of these studies.

Special appreciation is extended to Drs. Assur, Malcolm Mellor, Richard H. Munis, and Francis H. Sayles for fruitful discussions, valuable comments, and advice.

The contents of this report are not to be used for promotional purposes. Citation of brand names does not constitute an official endorsement or approval of the use of such commercial products. 


\section{CONTENTS}

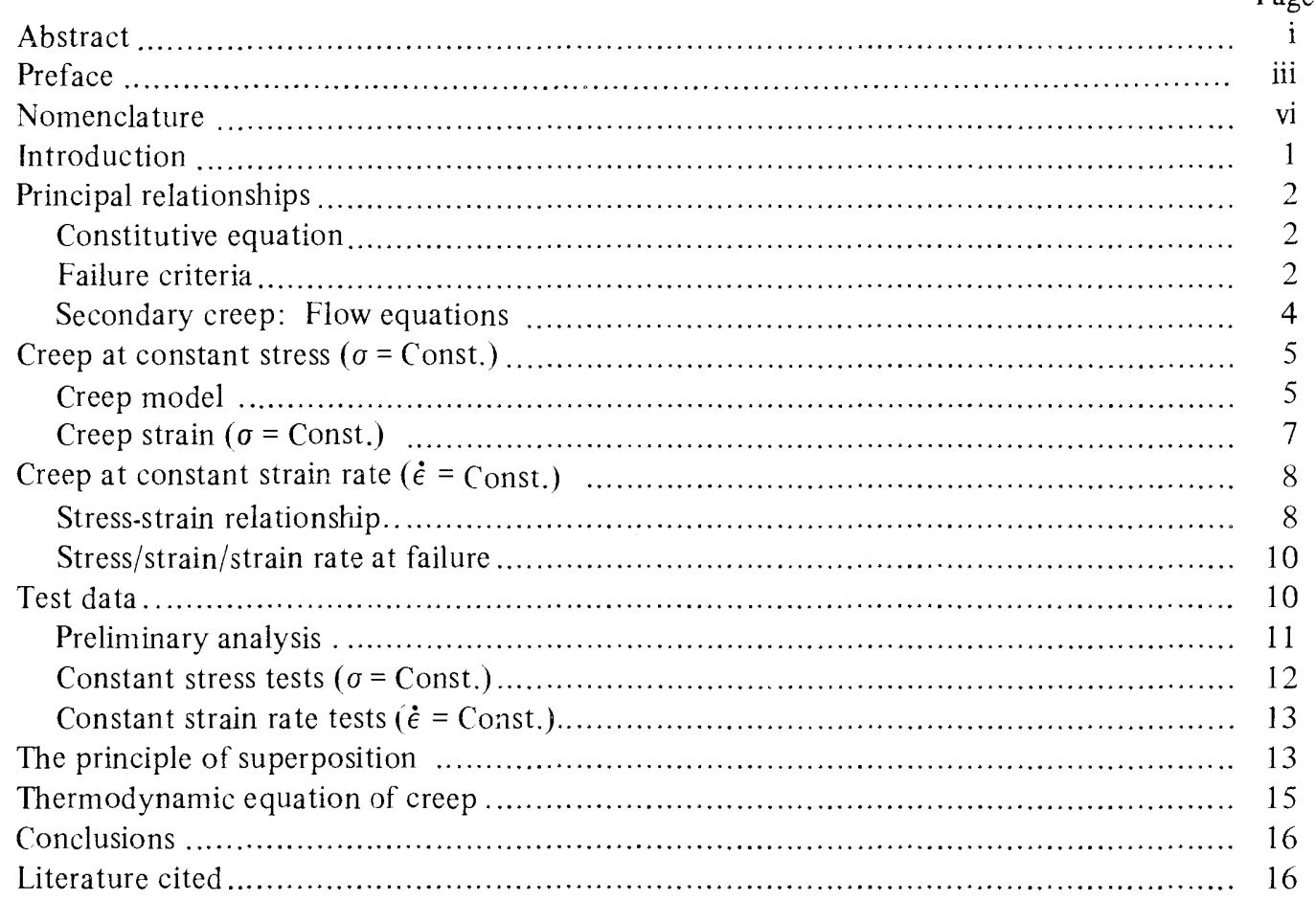

\section{ILLUSTRATIONS}

Figure

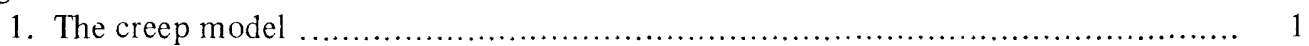

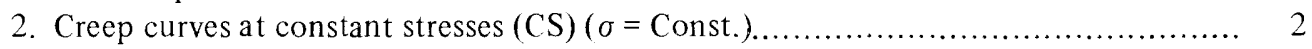

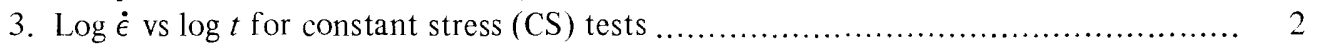

4. Stress-strain relationship at constant strain rates (CSR) ............................. 3

5. Time-dependent failure ......................................................... 3

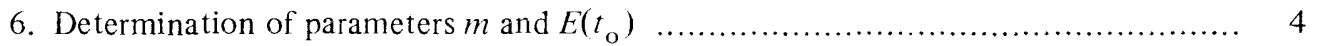

7. Rheological curve ............................................................ 5

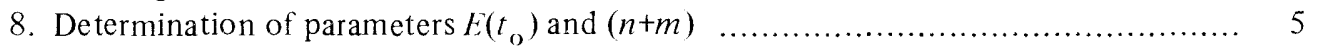

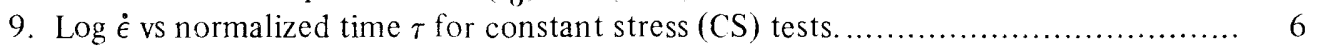

10. Normalized strain rates $\dot{\epsilon} / \dot{\epsilon}_{\mathrm{m}}$ vs normalized time $\tau$ for constant stress (CS) tests....... 6

11. Normalized stress $\left(\sigma_{\max } / \sigma\right)^{\mathrm{m}}$ vs normalized time $\tau$ for constant strain rate (CSR) tests 6

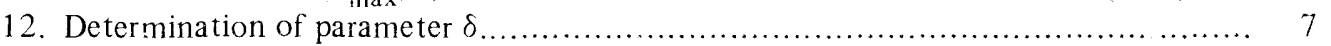

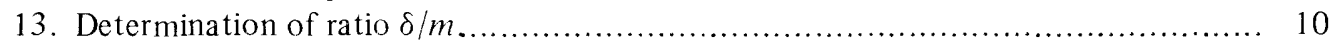

14. Diagram for calculation of secant modulus ...................................... 10

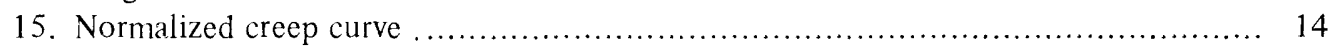

16. Normalized stress-strain curve ................................................... 14

17. Superposition of creep (CS) and constant strain rate (CSR) tests ................... 15

\section{TABLES}

Table

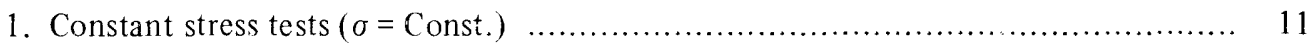

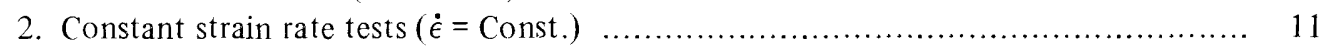




\section{NOMENCLATURE}

\begin{tabular}{|c|c|c|c|}
\hline$\tilde{C}, C$ & material constants & $\epsilon^{\mathfrak{c}}$ & creep strain \\
\hline$E$ & activation energy & $\epsilon_{\mathrm{m}}^{\mathrm{c}}$ & creep strain at failure \\
\hline$E$ & apparent (free) energy & $\epsilon_{\mathrm{f}}$ & failure strain as a failure \\
\hline$E_{\mathrm{m}}$ & secant modulus at failure & & criterion \\
\hline $\begin{array}{l}E_{\mathbf{o}} \\
E(\tau)=E(\check{\epsilon})\end{array}$ & $\begin{array}{l}\text { deformation modulus } \\
\text { secant modulus in CSR }\end{array}$ & $\epsilon_{\mathrm{m}}$ & $\begin{array}{l}\text { strain at failure in CSR } \\
\text { tests }\end{array}$ \\
\hline & tests & $\dot{\epsilon}$ & strain rate \\
\hline$h$ & Planck's constant & $\dot{\epsilon}_{*}$ & initial strain rate at time $t_{*}$ \\
\hline$k$ & Boltzmann's constant & $\dot{\epsilon}_{\mathrm{m}}$ & minimum strain rate \\
\hline$m$ & $\begin{array}{l}\text { stress-hardening param- } \\
\text { eter in failure criterion }\end{array}$ & $\dot{\epsilon}_{\mathrm{o}}$ & $\begin{array}{l}\text { strain rate corresponding to } \\
\text { instantaneous strength } \sigma_{\mathrm{o}}\end{array}$ \\
\hline$N$ & Avogadro's number & $\eta, \eta(\tau)$ & viscosity coefficient \\
\hline$n$ & stress-hardening param- & $\theta$ & test temperature \\
\hline & eter in flow equation & $\lambda$ & time-hardening parameter \\
\hline$p$ & mathematical probability & & as a function of $\delta$ \\
\hline $\begin{array}{l}R \\
T\end{array}$ & gas constant & $\xi$ & normalized strain in CS \\
\hline $\begin{array}{l}T \\
t\end{array}$ & absolute temperature & & tests \\
\hline$t$ & time & $\dot{\xi}, \dot{\xi}(\tau)$ & normalized strain rate in \\
\hline$t_{*}$ & initial time & & CS tests \\
\hline$t_{\mathrm{m}}$ & time to failure & $\xi_{\mathrm{m}}$ & normalized failure strain \\
\hline$t_{\mathrm{o}}$ & Frenkel's relaxation time & $\sigma$ & stress \\
\hline$t_{\mathrm{r}}$ & time to rupture & $\bar{\sigma}$ & normalized stress in CSR \\
\hline Y & superposition function & & tests \\
\hline$Y^{\prime}$ & $\begin{array}{l}\text { for CS tests } \\
\text { superposition function }\end{array}$ & $\sigma_{\max }$ & $\begin{array}{l}\text { peak value of stress in CSR } \\
\text { tests }\end{array}$ \\
\hline & for CSR tests & $\sigma_{0}$ & instantaneous strength \\
\hline$\Delta S, \Delta S(\tau)$ & $\begin{array}{l}\text { entropy increment as a } \\
\text { function of normalized }\end{array}$ & $\begin{array}{l}\sigma(\tau) \\
\tau\end{array}$ & $\begin{array}{l}\text { stress in CSR tests } \\
\text { normalized time }\end{array}$ \\
\hline$\Delta \stackrel{*}{S}, \Delta \stackrel{*}{S}(\tau)$ & $\begin{array}{l}\text { time } \tau \\
\text { entropy increment as a } \\
\text { function of stress ratios } \\
\left(\sigma_{\mathrm{o}} / \sigma\right) \text { and }\left(\sigma_{\max } / \sigma\right)\end{array}$ & $\begin{array}{l}\tau_{*} \\
\tau_{\mathrm{o}} \\
\psi\end{array}$ & $\begin{array}{l}\text { initial normalized time } \\
\text { normalized time to failure } \\
\text { integration factor for creep } \\
\text { strain } \epsilon^{\mathrm{c}}\end{array}$ \\
\hline$\delta$ & time-hardening parameter & $\psi_{\mathrm{m}}$ & integration constant for \\
\hline $\begin{array}{l}\epsilon \\
\bar{\sigma}\end{array}$ & strain in CSR tests & & creep strain at failure $\epsilon_{\mathrm{m}}^{\mathrm{c}}$ \\
\hline $\bar{\epsilon}$ & $\begin{array}{l}\text { normalized strain (time) } \\
\text { in CSR tests }\end{array}$ & $\omega$ & $\begin{array}{l}\text { thermodynamic probabil- } \\
\text { ity }\end{array}$ \\
\hline
\end{tabular}




\title{
THERMODYNAMIC MODEL OF CREEP AT CONSTANT STRESSES AND CONSTANT STRAIN RATES
}

\author{
Anatoly M. Fish
}

\section{INTRODUCTION}

It is known that ductile materials under applied constant stress experience creep deformation; failure occurs when the deformation reaches a certain value. Strain rates in such tests are functions of stress, time, temperature, and other factors. If the tests are performed so that the strain rate remains constant, the stress becomes a function of the strain rate and temperature. It is obvious that the physical-mechanical properties of the material, and consequently the rheological parameters of the creep model selected, cannot and must not depend upon the loading regime.

Until now there was no unified creep model capable of describing a material's behavior under both loading regimes in the wide spectrum of stress, time, and temperature. The strength characteristics of viscous materials (soils) were determined from constant strain rate (CSR) tests, while their deformation characteristics were determined from creep (CS) tests at constant stress. However, the deformation characteristics obtained from CSR tests did not correspond to those from CS tests. The absence of adequate information on the basic stress-strain relationship during creep affected the accuracy and reliability of solutions to practical problems.

In this paper for the first time the entire creep process, including primary, secondary, and tertiary creep, and failure, for both constant stress tests and constant strain rate tests, is described in the form of a unified constitutive equation and unified failure criteria. Regardless of the loading regime the mechanical properties of the material are described by the same param-

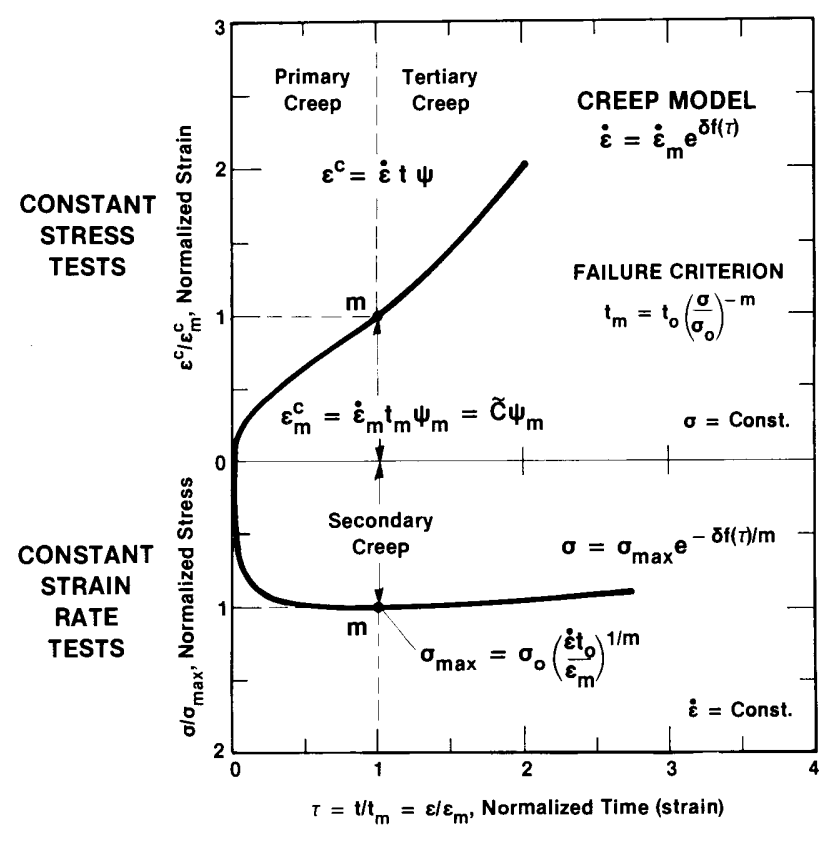

Figure 1. The creep model.

eters. Hence, information obtained from one type of test can be used to predict a material's behavior under another type of loading.

This creep model (Fig. 1) has been developed based upon several theoretical concepts:

- The Eyring-Frenkel Theory of Rate Processes (RPT)

- The thermodynamic nature of the strength of solids

- The unity of the process of deformation and time-dependent failure 
- The principle of the linear summation of defects in solids

- The concept of normalized strain, strain rate, stress, and time

A detailed derivation of the principal relationships of the model - that is, the constitutive equation, the flow equation, and the failure criteria based upon these concepts-is given in Fish (1983b). An approximate derivation of the model is given in Fish (1976a, 1980).

\section{PRINCIPAL RELATIONSHIPS}

\section{Constitutive equation}

A unified constitutive equation describing the entire creep process (including primary, secondary, and tertiary creep) and failure at constant stress has been derived by Fish (1976a; 1979; 1980; 1982a,b; 1983a, b):

$$
\dot{\epsilon}=\tilde{C} \frac{k T}{h} \exp \left(-\frac{E}{R T}\right) \exp \frac{\Delta S}{k}\left(\frac{\sigma}{\sigma_{\mathrm{o}}}\right)^{\mathrm{n}+\mathrm{m}}
$$

where $\tilde{C}, n \geqslant 0$, and $m \geqslant 1$ are dimensionless parameters independent of temperature

$\sigma_{\mathrm{O}}=$ temperature-dependent, ultimate strength of soil, $\mathrm{MPa}\left(\mathrm{kg} / \mathrm{cm}^{2}\right)$

$E=$ activation energy, $\mathrm{kJ} / \mathrm{mole}(\mathrm{kcal} / \mathrm{mole})$

$k=$ Boltzmann's constant, $1.38 \times 10^{-23} \mathrm{~J} /{ }^{\circ} \mathrm{K}$

$h=$ Planck's constant, $6.63 \times 10^{-34} \mathrm{Js}$

$R=$ gas constant, $8.31 \times 10^{-3} \mathrm{~kJ} /$ mole $\times{ }^{\circ} \mathrm{K}$

$T=$ absolute temperature, ${ }^{\circ} \mathrm{K}$

$k T / h=$ frequency of vibration of elementary particles around their equilibrium positions

$\Delta S=$ change of entropy (Fish 1983b)

$$
\frac{\Delta S}{k}=\frac{\Delta S(\tau)}{k}=\delta f(\tau)
$$

$\delta=$ a dimensionless parameter independent of temperature

$f(\tau)=$ a function of normalized (dimensionless) time

$$
f(\tau)=\tau-\ln \tau-1
$$

and

$$
\begin{gathered}
\tau=t / t_{\mathrm{m}} \\
t_{\mathrm{m}}=\text { the time to failure. }
\end{gathered}
$$

The creep process is assumed to be isothermal, and volumetric and instantaneous strains are assumed to be small.

\section{Failure criteria}

When $t=t_{\mathrm{m}}, \tau=1$, and $f(1)=0$, the strain rate reaches the minimum $\left(\dot{\epsilon}_{\mathrm{m}}\right)$ (points $m$ in Figs. 2 and 3), and failure occurs. The failure state is characterized by the thermodynamic failure criterion (Fish 1983b)

$$
\Delta S=0 .
$$

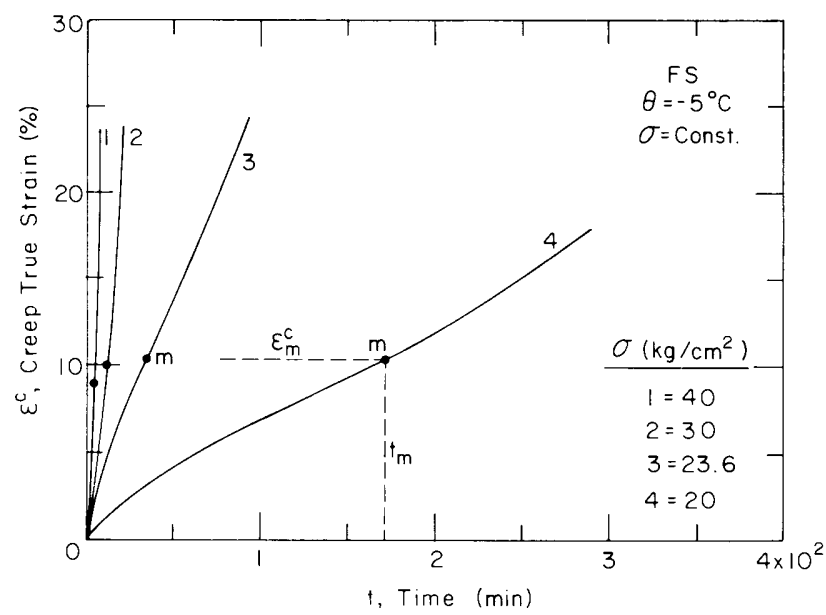

Figure 2. Creep curves at constant stresses (CS) $(\sigma=$ Const.). Data from $\mathrm{Zhu}$ and Carbee (1983b). $\mathrm{m}$ are the inflection points, $\epsilon_{m}^{c}$ is the creep strain at failure, and $\mathrm{t}_{m}$ is the time to failure.

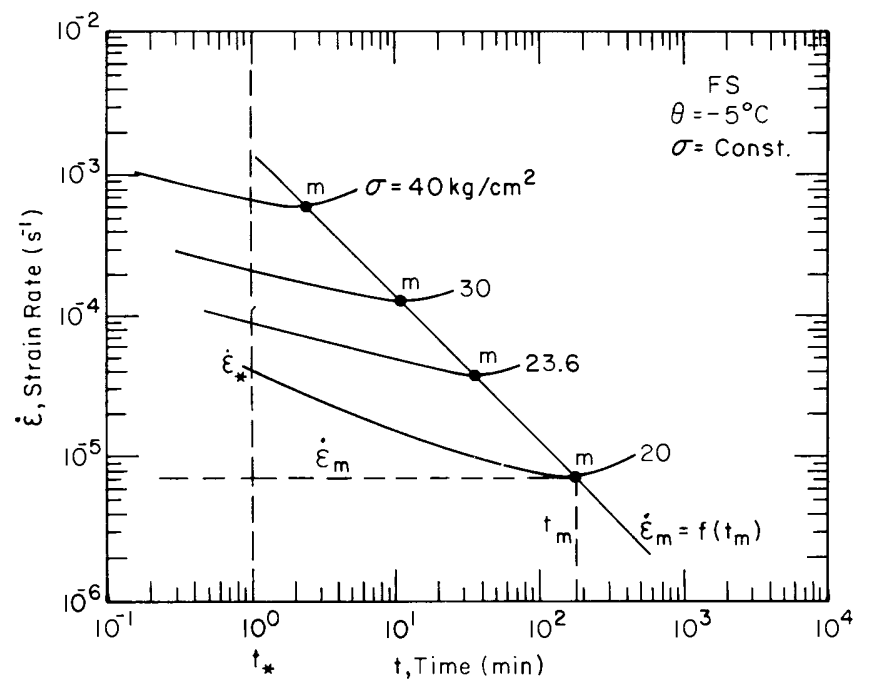

Figure 3. Log $\dot{\epsilon}$ vs $\log \mathrm{t}$ for constant stress (CS) tests. Data from Zhu and Carbee (1983a). m are the inflection points, $\dot{\epsilon}_{m}$ is the minimum strain rate, $\mathrm{t}_{m}$ is the time to failure, $\dot{\epsilon}_{*}$ is the initial strain rate, and $\mathrm{t}_{*}$ is the initial time. 
Time to failure $t_{\mathrm{m}}$ is linked to applied stress $\sigma$ by the relationship derived by Fish $(1976 a, b ; 1979 ; 1980$; 1982a,b; 1983a,b):

$$
t_{\mathrm{m}}=t_{\mathrm{o}}\left(\frac{\sigma}{\sigma_{\mathrm{o}}}\right)^{-\mathrm{m}} \text { for } \sigma \leqslant \sigma_{\mathrm{o}}
$$

where $t_{0}$ is the mean duration of the "settled life" of an elementary particle in a position of equilibrium (Frenkel 1947):

$$
t_{\mathrm{o}} \approx \frac{h}{k T} e^{\mathrm{E} / \mathrm{RT}}
$$

and $h / k T$ is the period of the vibrations of the elementary particles around their equilibrium positions.

It follows from eq 5 that of all the values of failure stress $\sigma_{\max }$ obtained from CSR tests (Fig. 4), only one stress, $\sigma_{o}$, causes failure at time $t_{0}$. The basic postulate of this author is that time $t_{\mathrm{o}}$ is equal to Frenkel's relaxation time (eq 6). The stress at time $t_{\mathrm{m}}=t_{\mathrm{o}}$ is defined as the instantaneous strength of the soil $\sigma_{0}$.

The detailed derivation of failure criterion eq 5 and the physical sense of the stress ratio are given in Fish (1983b), where it was shown that

$$
\tau_{\mathrm{o}}=\frac{t_{\mathrm{m}}}{t_{\mathrm{o}}}=\left(\frac{\sigma_{\mathrm{o}}}{\sigma}\right)^{\mathrm{m}}=\frac{1}{p}=\omega
$$

where $\tau_{\mathrm{o}}$ is the normalized time to failure and $\omega$ and $p$ are the thermodynamic and mathematical probabilities, respectively, of the concentration of $m$ defects (microcracks) in the unit volume of the material (soil). According to eq 7 , time to failure $t_{\mathrm{m}}$ is in fact the product

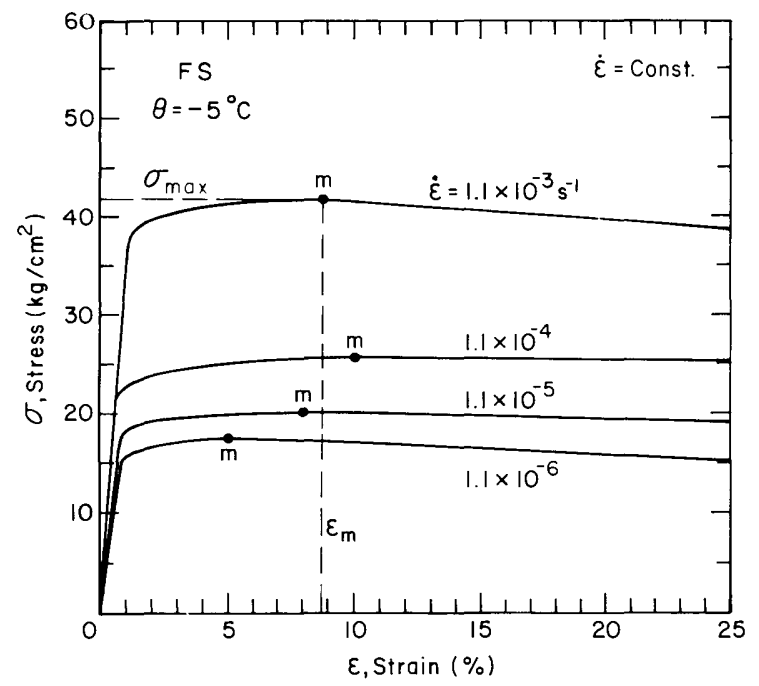

Figure 4. Stress-strain relationship at constant strain rates (CSR). Data from Zhu and Carbee (1983b). $\mathrm{m}$ are the inflection points, $\epsilon_{m}$ is the failure strain, and $\sigma_{\max }$ is the peak value of stress.

$$
t_{\mathrm{m}}=t_{\mathrm{o}} \omega
$$

Since stress $\sigma \leqslant \sigma_{0}, \omega$ changes from unity up to infinity, so the time to failure cannot be smaller than time $t_{\mathrm{o}}$.

If the magnitudes of $t_{\mathrm{o}}$ obtained from tests are smaller than those calculated by eq 6 using the appropriate values of the activation energy, the loading regime is considered to be dynamic (i.e. an impact loading regime) rather than static. At the same time, at high strain rates (Sayles and Epanchin 1966, Gold 1973, Bragg and Andersland 1980) the times $t_{\mathrm{o}}$ may vary while the magnitude of $\sigma_{0}$ remains unchanged. However, the times $t_{\mathrm{o}}$ are small and, for practical purposes, such variations in $t_{\mathrm{o}}$ are insignificant.

Note that by definition the logarithm of $\omega$ is, with accuracy up to a constant, the entropy, i.e.

$$
\frac{\Delta S}{k}=\ln \omega=\ln \tau_{\mathrm{o}}=m \ln \left(\frac{\sigma_{\mathrm{o}}}{\sigma}\right) .
$$

$\Delta \stackrel{*}{S}$ reflects the change of the entropy caused by the application of stress. Equation 9 is the thermodynamic failure criterion for constant stress (CS) tests. For constant strain rate (CSR) tests, when $\sigma=\sigma_{\max }$, the thermodynamic failure criterion is

$$
\frac{\Delta \stackrel{*}{S}}{k}=\ln \tau_{\mathrm{o}}=m \ln \left(\frac{\sigma_{\mathrm{o}}}{\sigma_{\max }}\right) .
$$

When $\sigma=\sigma_{\text {max }}=\sigma_{o}$, eqs 9 and 9 a yield the failure criterion

$$
\Delta \stackrel{*}{S}=0
$$

The validity of eqs 9 and $9 \mathrm{a}$ is shown below (Figs. 5 and 6) using test data on creep of frozen soil at constant stresses and at constant strain rates.

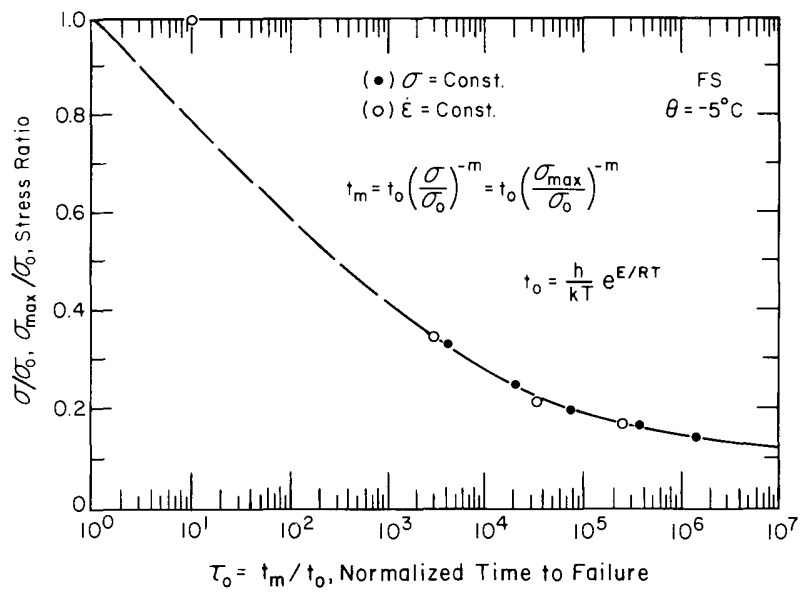

Figure 5. Time-dependent failure. 


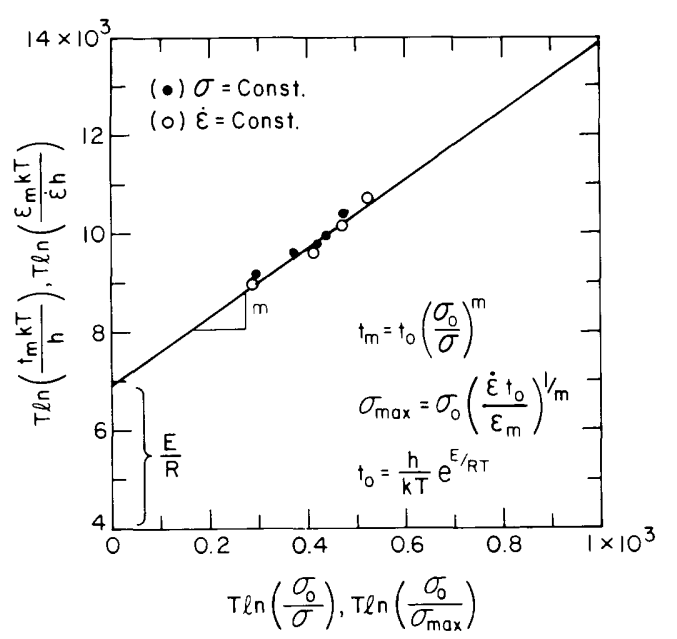

Figure 6. Determination of parameters $\mathrm{m}$ and $\mathrm{E}\left(\mathrm{t}_{o}\right)$.

\section{Secondary creep: Flow equations}

When $t=t_{\mathrm{m}}, \tau=1$, and $f(1)=0$, then the strain rate $\dot{\epsilon}$ becomes $\dot{\epsilon}_{\mathrm{m}}$. According to eq 1 , there can be three types of relationships between the minimum strain rate $\dot{\epsilon}_{\mathrm{m}}$ and the applied stress $\sigma$ with respect to the value of parameter $n$.

General case $(0<n \neq 1)$

In this case, $\Delta S=0$ and eq 1 becomes (Fish 1979; $1980 ; 1982 \mathrm{a}, \mathrm{b})$

$$
\dot{\epsilon}_{\mathrm{m}}=\tilde{C} \frac{k T}{h} \exp \left(-\frac{E}{R T}\right)\left(\frac{\sigma}{\sigma_{\mathrm{o}}}\right)^{\mathrm{n}+\mathrm{m}} .
$$

Combining eqs 5,6 , and 10 ,

$$
\dot{\epsilon}_{\mathrm{m}}=\frac{\tilde{C}}{t_{\mathrm{o}}}\left(\frac{\sigma}{\sigma_{\mathrm{o}}}\right)^{\mathrm{n}+\mathrm{m}}=\frac{\tilde{C}}{t_{\mathrm{m}}}\left(\frac{\sigma}{\sigma_{\mathrm{o}}}\right)^{\mathrm{n}} .
$$

Denoting $C=e^{\delta} \tilde{C}$ and

$$
t_{\mathrm{r}}=e^{\delta} t_{\mathrm{o}}\left(\frac{\sigma_{\mathrm{o}}}{\sigma}\right)^{\mathrm{n}+\mathrm{m}}=e^{\delta} t_{\mathrm{m}}\left(\frac{\sigma}{\sigma_{\mathrm{o}}}\right)^{-\mathrm{n}},
$$

eq 11 takes the form

$$
\dot{\epsilon}_{\mathrm{m}}=\frac{C}{t_{\mathrm{r}}}=\frac{\text { Const. }}{t_{\mathrm{r}}}
$$

where the time to rupture, $t_{\mathrm{r}}>t_{\mathrm{m}}$, is the time to the complete destruction of the sample (not shown in Figs. 1,2, and 3). The relationship in eq 13 has been confirmed by test data for a great variety of materials (Regel et al. 1974).

Note that stress $\sigma_{\mathrm{o}}$ in eqs 1 through 12 is not merely a reference unit to balance the dimensions of stress, but is a definite strength characteristic depend. ent upon temperature and determined from constant strain rate (CSR) tests at a definite (non-arbitrary) rate of deformation. The mathematical structure of the stress ratio $\left(\sigma / \sigma_{\mathrm{o}}\right)$ is identical to that given by Nadai (1950), Rabotnov (1966), Ladanyi (1972), and others. From the physical viewpoint, parameter $\sigma_{o}$ may be considered to be the strength of the material's crystalline lattice (Garofalo 1965) or of the soil structure.

\section{Generalized Newtonian law}

of viscous flow $(n=1)$

If $n=1$, then denoting, as suggested by Fish (1976a, $1979,1983 b$ ),

$$
E_{\mathrm{o}}=\frac{\sigma_{\mathrm{o}}}{\tilde{C}} \quad \text { and } \quad \eta=E_{\mathrm{o}} t_{\mathrm{o}}
$$

and combining eqs 11 and 14 ,

$$
\dot{\epsilon}_{\mathrm{m}}=\frac{\sigma}{E_{\mathrm{o}} t_{\mathrm{o}}}\left(\frac{\sigma}{\sigma_{\mathrm{o}}}\right)^{\mathrm{m}}=\frac{\sigma}{E_{\mathrm{o}} t_{\mathrm{m}}}
$$

or

$$
\dot{\epsilon}_{\mathrm{m}}=\frac{\sigma}{\eta} \cdot \frac{t_{\mathrm{o}}}{t_{\mathrm{m}}}=\frac{\sigma}{\eta} p=\frac{\sigma}{\eta} \cdot \frac{1}{\omega},
$$

where $p$ and $w$ are the mathematical and thermal probabilities, respectively. Equation 16 can be considered as a generalized law of Newtonian viscous flow. When $n=0$ and $m=1$ (see below), eq 16 transforms in to Newton's law of viscosity,

$$
\dot{\epsilon}_{\mathrm{m}}=\frac{\sigma}{\eta}
$$

and parameters $t_{\mathrm{o}}, E_{\mathrm{o}}$, and $\eta$ gain a physical sense of Frenkel's relaxation time, a deformation modulus, and a viscosity coefficient, respectively (Frenkel 1947).

Equations 14 and 15 establish the strongest links between the deformation modulus of soil, the viscosity coefficient, soil strength and, as will be shown, the critical failure strain.

Particular case $(n=0)$

The case when $n=0$ implies that the slope of the plot ( $\log \dot{\epsilon}_{\mathrm{m}}$ vs $\left.\log t_{\mathrm{m}}\right)$ is equal to -1 (Figs. 3, 7, and $8)$, i.e.

$$
\dot{\epsilon}_{\mathrm{m}}=\frac{\tilde{C}}{t_{\mathrm{o}}}\left(\frac{\sigma}{\sigma_{\mathrm{o}}}\right)^{\mathrm{m}}=\frac{\tilde{C}}{t_{\mathrm{m}}}
$$




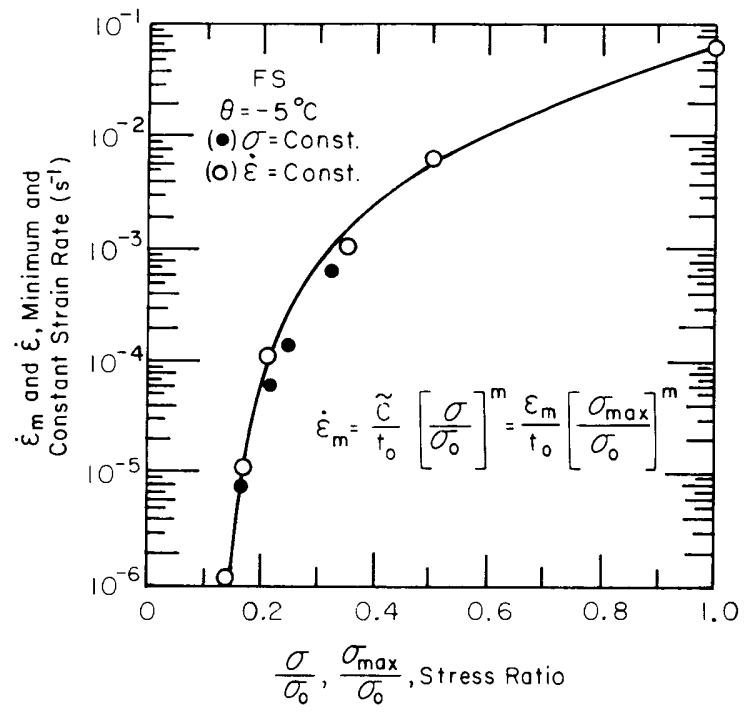

Figure 7. Rheological curve.

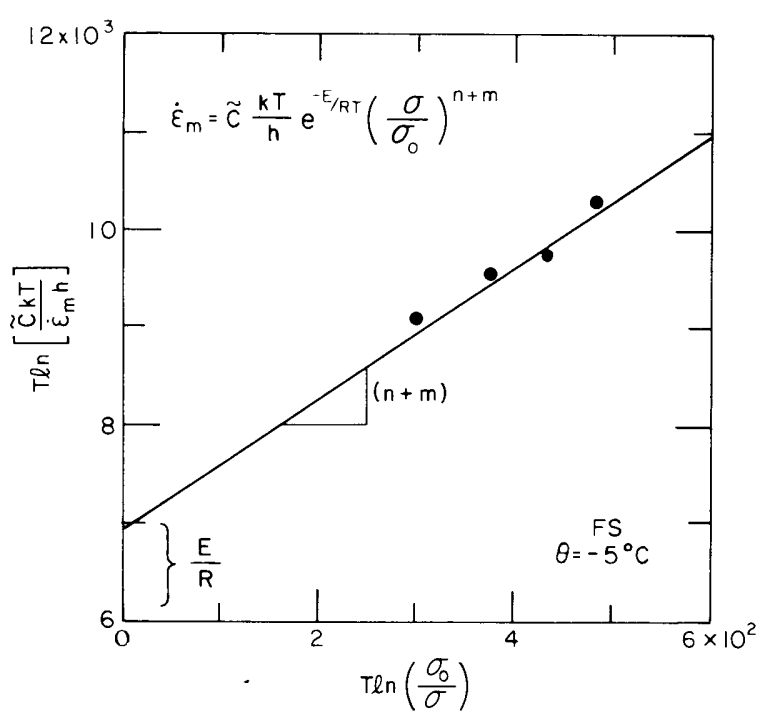

Figure 8. Determination of parameters $\mathrm{E}\left(\mathrm{t}_{o}\right)$ and $(\mathrm{n}+\mathrm{m})$.

This concept is supported by Ladanyi (1972), Mitchell (1976), Assur (1980), and partially by Mellor and Cole (1983), and others. It is assumed that in short-term creep the inflection points of the transition from primary creep to tertiary creep are clearly distinguishable. In practice, however, it can be difficult to find the precise locations of inflection points $m$ and to determine accurately times to failure $t_{\mathrm{m}}$. For shortterm creep, slight variations of the absolute values of $t_{\mathrm{m}}$ (and $n$ ) do not affect substantially the results of the final creep strain calculations.

It is also possible (Regel et al. 1974) that the slope of the plot $\left(\log \dot{\epsilon}_{\mathrm{m}}\right.$ vs $\left.\log t_{\mathrm{m}}\right)$ is not equal to $-1(n \neq 0)$, as described by eqs 10 and 13 . Analysis of test data for various materials (Ladanyi 1972) and for frozen soil (Zhu and Carbee 1983a) shows that the deviation from $n=0$ is not substantial. From tests on frozen Fairbanks silt, the value of $n$ is found to be within the limits $0<n<1$ over a wide spectrum of stresses and temperatures. Therefore, when comparing creep at constant stress and constant strain rates, the value of $n$ can be ignored.

\section{CREEP AT CONSTANT STRESS $(\sigma=$ CONST $)$}

\section{Creep model}

The principal concept of this creep model is that deformation and failure compose a unified process that can be described by a unified constitutive equation with only one parameter, $\delta$.

Combining eqs 1, 2, and 10, we obtain (Fish 1983b, Fish and Assur 1983),

$$
\dot{\epsilon}=\dot{\epsilon}_{\mathrm{m}} e^{\delta \mathrm{f}(\tau)}
$$

where, as a first approximation, the function

$$
f(\tau)=\tau-\ln \tau-1 \text { and } \tau=t / t_{\mathrm{m}} .
$$

The creep process can therefore be characterized by the values of normalized time $\tau$, strain rate $\dot{\xi}=\dot{\epsilon} / \dot{\epsilon}_{\mathrm{m}}$ (see eq 22 below), and the corresponding value of function $f(\tau)$ :

$$
\begin{array}{llll}
\text { Primary creep } & \tau<1 & f(\tau)>0 & \dot{\xi}>1 \\
\text { Secondary creep } & \tau=1 & f(1)=0 & \dot{\xi}=1 \\
\text { Tertiary creep } & \tau>1 & f(\tau)>0 & \dot{\xi}>1
\end{array}
$$

Equation 19 implies that the duration of secondary creep is zero (point $m$ in Fig. 1). In developing this model it was assumed that the major cause of deformation is the failure process, which is initia ted at the very start of deformation as soon as the constant load, however small, is applied to the sample.

Equation 19 belongs to the general family of creep models derived from various assumptions by Zaretskii and Vialov (1971) and Vialov et al. (1973) and by Fish $(1976 a, 1979,1980)$. The simplest conceptual approach leading to eq 19 was given by Assur (1980). The relationship of this equation to primary creep models was considered by Fish and Sayles (1981).

Generalized model of viscous flow

If $n=1$, combining eqs 15 and 19 (Fish 1979) gives 

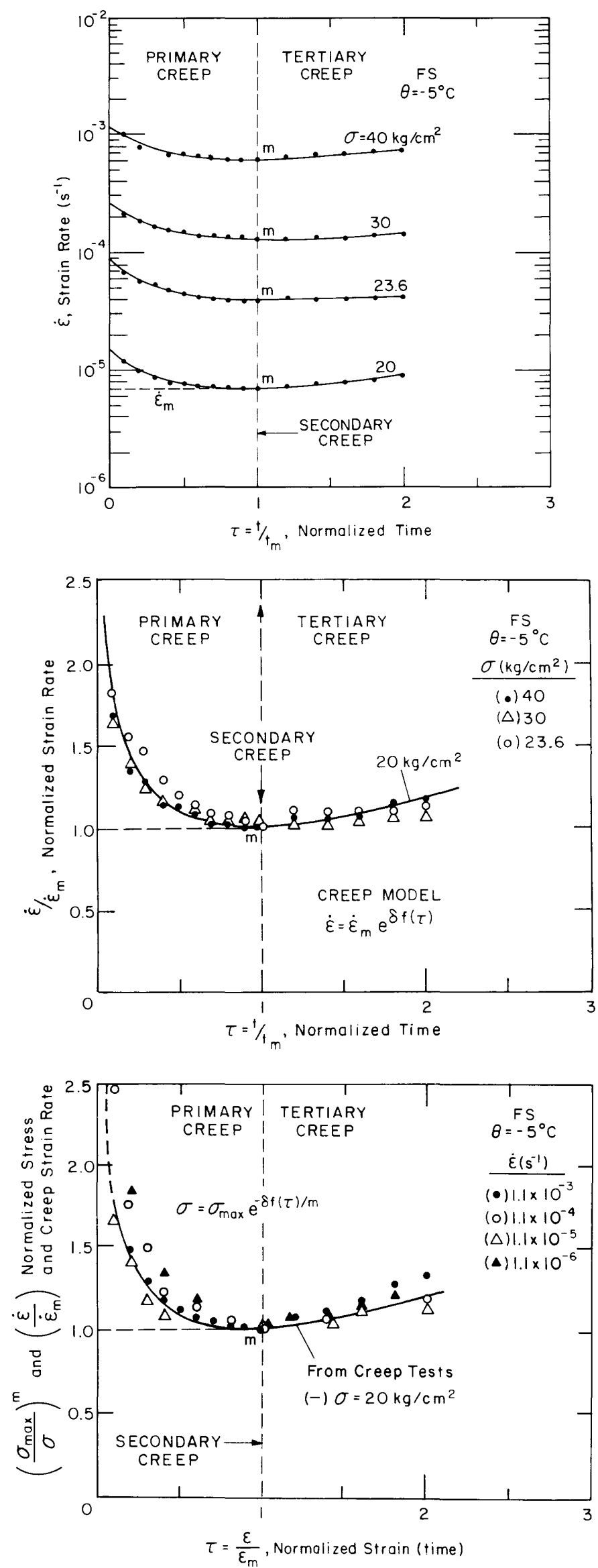

Figure 9. Log $\dot{\epsilon}$ vs normalized time $\tau$ for constant stress (CS) tests. mare inflection points.

Figure 10. Normalized strain rates $\dot{\epsilon} \mid \dot{\epsilon}_{m}$ vs normalized time $\tau$ for constant stress (CS) tests. $\mathrm{m}$ is the inflection point.

Figure 11. Normalized stress $\left(\sigma_{\max } / \sigma\right)^{m}$ vs normalized time $\tau$ for constant strain rate (CSR) tests. $\mathrm{m}$ is the inflection point. 


$$
\dot{\epsilon}=\frac{\sigma}{\eta(\tau)}
$$

where the function

$$
\eta(\tau)=E_{\mathrm{o}} t_{\mathrm{m}} e^{-\delta \mathrm{f}(\tau)}
$$

is the coefficient of viscosity, which is dependent on stress, temperature, and the normalized time $\tau$.

\section{Normalized creep strain rate}

According to eq 19, the behavior of various materials during creep, regardless of stress, temperature, or time, can be described by a unified constitutive equation:

$$
\dot{\xi}=\frac{\dot{\epsilon}}{\dot{\epsilon}_{\mathrm{m}}}=e^{\delta \mathrm{f}(\tau)}
$$

where $\dot{\xi}$ is the normalized (dimensionless) strain rate (Figs. 9 and 10). Thus, all the specifics of a material's behavior with respect to time are expressed by the magnitude of parameter $\delta$ :

$$
\delta=\frac{\ln \left(\dot{\epsilon} / \dot{\epsilon}_{\mathrm{m}}\right)}{f(\tau)} .
$$

The material's behavior, with respect to stress and temperature, is characterized by the absolute values of parameters $t_{o}, \sigma_{o}, m$, and $n$, which compose flow equation eq 10 and failure criterion eq 5 .

Note that from the physical viewpoint the change in the normalized strain rate over time reflects the change of the entropy increment, i.e.

$$
\dot{\xi}(\tau)=\exp \frac{\Delta S}{k} .
$$

This relationship is shown in Figures 10 and 11 .

At secondary creep, when $t=t_{\mathrm{m}}, \tau=1$, and $f(1)=0$, then regardless of the material type, stress, or temperature eqs 22 and 24 yield the failure criterion

$$
\dot{\xi}=1 \text {, }
$$

which corresponds to eq 4.

Parameter $\delta$ can be found from Figure 12 as a slope of the straight line, or it may be calculated at any moment of time:

$$
\delta=\frac{\ln \left(\dot{\epsilon}_{*} / \dot{\epsilon}_{\mathrm{m}}\right)}{\tau_{*}-\ln \tau_{*}-1}
$$

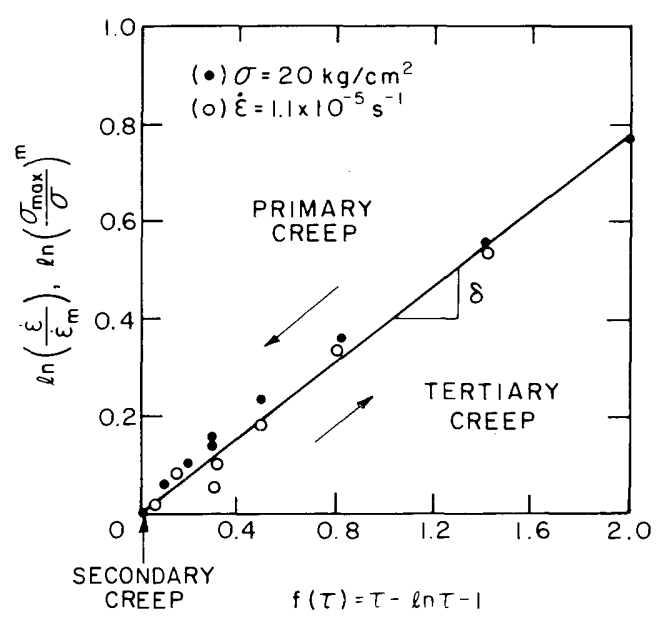

Figure 12. Determination of parameter $\delta$.

where $\tau_{*}=t_{*} / t_{\mathrm{m}}, t_{*}$ is the initial (or any selected) time, and $\dot{\epsilon}_{*}$ is the corresponding strain rate (Fig. 3 ).

\section{Creep strain ( $\sigma=$ Const.)}

General case $(0<n \neq 1)$

The tabulated integral of eq 19 for $\delta \neq 1$ (Fish 1983b, Fish and Assur 1983) gives an equation for creep strain $\epsilon^{\mathrm{c}}$ :

$$
\epsilon^{\mathrm{c}}=\dot{\epsilon} t \psi
$$

or

$$
\epsilon^{\mathrm{c}}=\dot{\epsilon}_{\mathrm{m}} t_{\mathrm{m}} \psi \tau e^{\delta \mathrm{f}(\tau)}
$$

where $\psi$ is the integration factor. The instantaneous strain is assumed to be small and can be ignored.

Combining eqs 11 and 27 ,

$$
\epsilon^{\mathrm{c}}=\tilde{C}\left(\frac{\sigma}{\sigma_{\mathrm{o}}}\right)^{\mathrm{n}} \psi \tau e^{\delta \mathrm{f}(\tau)}
$$

and

$$
\psi=\frac{1}{\lambda}\left[1-\frac{\delta \tau}{1+\lambda}+\frac{(\delta \tau)^{2}}{(1+\lambda)(2+\lambda)}-\ldots\right]
$$

in which $\lambda=1-\delta$.

Experiments have shown that for frozen soils, $0<\delta<1$. In general, six terms of the series (eq 29) provide sufficiently accurate calculations of creep strain. For preliminary analyses, when $0<\delta \leqslant 0.3$ and $t \leqslant t_{\mathrm{m}}$, the calculations can be simplified by retaining the first term of the series (Fish 1982a, 1983a). 
Strain at failure

When $t=t_{\mathrm{m}}, \tau=1$, and $f(1)=0$, then eqs 26,27, and 28 yield

$$
\epsilon_{\mathrm{m}}^{\mathrm{c}}=\dot{\epsilon}_{\mathrm{m}} t_{\mathrm{m}} \psi_{\mathrm{m}}
$$

or

$$
\epsilon_{\mathrm{m}}^{\mathrm{c}}=\tilde{C}\left(\frac{\sigma}{\sigma_{\mathrm{o}}}\right)^{\mathrm{n}} \psi_{\mathrm{m}}
$$

where $\epsilon_{\mathrm{m}}^{\mathrm{c}}$ is creep strain at failure and integration constant $\psi_{\mathrm{m}}$ is given by

$$
\psi_{\mathrm{m}}=\frac{1}{\lambda}\left[1-\frac{\delta}{(1+\lambda)}+\frac{\delta^{2}}{(1+\lambda)(2+\lambda)}-\ldots\right]
$$

where $\lambda=1-\delta$. Since $\sigma_{o}$ is temperature-dependent, it follows that in the general case the magnitude of strain at the moment of failure is a function of stress and temperature.

\section{Particular case $(n=1)$}

If $n=1$, we can combine eqs 15 and 27 to obtain

$$
\epsilon^{\mathrm{c}}=\frac{\sigma}{E_{\mathrm{o}}} \psi \tau e^{\delta \mathbf{f}(\tau)}
$$

When $t=t_{\mathrm{m}}, \tau=1$, and $f(1)=0$, eq 33 becomes

$$
\epsilon_{\mathrm{m}}^{\mathrm{c}}=\frac{\sigma}{E_{\mathrm{o}}} \psi_{\mathrm{m}} .
$$

Equation 34 establishes an important linear relationship, similar to that of Hooke's law, between the applied stress and the strain at failure. In practice, however, such a dependency may not always be recognizable because of variations in the soil properties, which are expressed in variations of $\delta, E_{\mathrm{o}}$, and $n$.

\section{Particular case $(n=0)$}

If $n=0$, the calculation of strain by eq 28 is simplified, i.e.

$$
\epsilon^{\mathfrak{c}}=\tilde{C} \psi \tau e^{\delta \mathrm{f}(\tau)}
$$

When $t=t_{\mathrm{m}}, \tau=1$, and $f(1)=0$, eq 35 yields

$$
\epsilon_{\mathrm{m}}^{\mathrm{c}}=\tilde{C} \psi_{\mathrm{m}}=\text { Const. }=\epsilon_{\mathrm{f}}
$$

where $\epsilon_{\mathrm{f}}$ is the failure strain.

Equation 36 indicates that failure strain $\epsilon_{\mathrm{f}}$ is constant regardless of stress and temperature and can be considered as the failure criterion for frozen soil and ice (Ladanyi 1972, Assur 1980, Mellor and Cole 1982, Zhu and Carbee 1983a).

\section{Normalized creep curve}

Creep curves obtained for various materials, regardless of the magnitude of applied stress and temperature, can be superposed on one universal plot, as shown in Figure 1, and they can be analyzed and described by a single equation. Combining eqs 27 and 30 ,

$$
\xi=\frac{\epsilon^{\mathrm{c}}}{\epsilon_{\mathrm{m}}^{\mathrm{c}}}=\frac{\psi}{\psi_{\mathrm{m}}} \tau e^{\delta \mathrm{f}(\tau)}
$$

where $\xi$ is the normalized creep strain. At secondary creep, when $\tau=1$ and $f(1)=0$, regardless of the material type, stress, or temperature, the failure criterion takes the form

$$
\xi_{\mathrm{m}}=1
$$

where $\xi_{\mathrm{m}}$ is the normalized failure strain.

In an approximate form eq 37 yields

$$
\xi=\frac{\epsilon^{\mathrm{c}}}{\epsilon_{\mathrm{m}}^{\mathrm{c}}} \approx \tau e^{\delta_{1} \mathrm{f}_{1}(\tau)}
$$

where $\epsilon_{\mathrm{m}}^{\mathrm{c}}$ is given by eqs $30,31,34$, or 36 , in which

$$
\psi_{\mathrm{m}} \approx 1 /(1-\delta)^{1 / 2}, \quad \delta<1
$$

is obtained by retaining the first two terms in eq 32 ,

$$
\begin{aligned}
& f_{1}(\tau)=\tau-\delta \ln \tau / \delta_{1}-1, \quad \text { and } \\
& \delta_{1}=\delta+(1-\delta)^{1 / 2}-1=\frac{1}{\psi_{\mathrm{m}}}-\frac{1}{\psi_{\mathrm{m}}^{2}}
\end{aligned}
$$

Equation 38 combines both the simplicity and the satisfactory accuracy of the creep strain calculations, and retains the basic assumptions, the parameters of the model, and their physical sense.

\section{CREEP AT CONSTANT STRAIN $\operatorname{RATE}(\dot{\epsilon}=$ CONST.$)$}

\section{Stress-strain relationship}

If the tests are performed at a constant strain rate ( $\dot{\epsilon}=\dot{\epsilon}_{\mathrm{m}}=$ Const.), stress $\sigma$ in eqs 1 and 9 becomes a function of the strain rate and the strain. For CSR tests, assuming that strains are small, i.e., 


$$
\epsilon=\dot{\epsilon} t, \quad \epsilon_{\mathrm{m}}=\dot{\epsilon} t_{\mathrm{m}},
$$

and

$$
\frac{\epsilon}{\epsilon_{\mathrm{m}}}=\bar{\epsilon}=\frac{t}{t_{\mathrm{m}}}=\tau
$$

Combining eqs 10 and 39 and taking into account that when $\epsilon=\epsilon_{\mathrm{m}}$ (Figs. 1 and 4) the stress reaches a peak (maximum):

$$
\sigma_{\max }=\sigma_{\mathrm{o}}\left(\frac{\dot{\epsilon} t_{\mathrm{o}}}{\tilde{C}}\right)^{\frac{1}{\mathrm{n}+\mathrm{m}}} .
$$

At the same time, we can combine failure criterion eq 5 and eq 39 :

$$
\sigma_{\max }=\sigma_{\mathrm{o}}\left(\frac{\dot{\epsilon} t_{\mathrm{o}}}{\epsilon_{\mathrm{m}}}\right)^{\frac{1}{\mathrm{~m}}}
$$

Comparing eqs 40 and 41 , we see that the simplest way to relate CSR tests and CS tests is to assume that the strains are small and that

$$
n=0 \quad \text { and } \quad \tilde{C} \equiv \epsilon_{\mathrm{m}} .
$$

Equation 41 is in agreement with the failure criteria for CSR tests suggested by Sayles and Epanchin (1966), Ladanyi (1972), Bragg and Andersland (1980), Mellor and Cole (1983), and others.

Combining eqs $10,19,41$, and 42 , a constitutive equation and a failure criterion for tests at constant strain rates take the forms

$$
\sigma=\sigma(\tau)=\sigma_{\max } e^{-\delta \mathrm{f}(\tau) / \mathrm{m}}
$$

and

$$
t_{\mathrm{m}}=\frac{\epsilon_{\mathrm{m}}}{\dot{\epsilon}}=t_{\mathrm{o}}\left(\frac{\sigma_{\max }}{\sigma_{\mathrm{o}}}\right)^{-\mathrm{m}}
$$

respectively. Time-dependent failure in CSR tests is shown in Figure 5. Since in CSR tests $\dot{\epsilon}=\dot{\epsilon}_{\mathrm{m}}$, eq 44 can be presented in the form of a flow equation similar to eq 18 :

$$
\dot{\epsilon}=\dot{\epsilon}_{\mathrm{m}}=\frac{\epsilon_{\mathrm{m}}}{t_{\mathrm{o}}}\left(\frac{\sigma_{\max }}{\sigma_{\mathrm{o}}}\right)^{\mathrm{m}} .
$$

The rheological curve obtained from the CSR tests is presented in Figure 7.

\section{Normalized stress-strain curve}

Thus, three principal relationships have been obtained that compose the creep model: the flow equation (eq 44a), the failure criterion (eq 44), and the stress-strain relationship (eq 43) are sufficient to describe the entire creep process during constant strain rate tests.

Determining the parameters is substantially simplified if all the test data are presented in normalized form, as in Figure 1. Thus, denoting $\bar{\sigma}=\sigma / \sigma_{\max }$ gives

$$
\bar{\sigma}=\frac{\sigma}{\sigma_{\max }}=e^{-\delta \mathbf{f}(\tau) / \mathrm{m}}
$$

or

$$
\frac{\sigma_{\max }}{\sigma}=e^{\delta \mathrm{f}(\tau) / \mathrm{m}}
$$

We can conclude that in CSR tests deformation and failure also compose a unified process that can be described by a single equation with only one parameter, $\delta / m$ :

$$
\frac{\delta}{m}=\frac{\ln \left(\sigma_{\max } / \sigma\right)}{f(\tau)}
$$

where $f(\tau)$ given by eq 3 is

$$
f(\tau)=\tau-\ln \tau-1 \text { and } \tau=t / t_{\mathrm{m}}
$$

Note that eq 45 can be rewritten in the form

$$
\left(\frac{\sigma \max }{\sigma}\right)^{\mathrm{m}}=e^{\delta \mathrm{f}(\tau)}=\exp \frac{\Delta S}{k}
$$

which is in agreement with eqs 2,9 , and 24 . This relationship with respect to $\tau$ is shown in Figure 11 .

By analogy with creep at constant stress, the deformation process at a constant strain rate can be characterized by the values of the normalized time (strain) $\tau$, stress $\widetilde{\sigma}$, and the corresponding value of function $f(\tau)$ :

$$
\begin{array}{llll}
\text { Primary creep } & \tau<1 & f(\tau)>0 & \bar{\sigma}<1 \\
\text { Secondary creep } & \tau=1 & f(1)=0 & \bar{\sigma}=1 \\
\text { Tertiary creep } & \tau>1 & f(\tau)>0 & \bar{\sigma}<1
\end{array}
$$


As in the case of short-term creep at constant stress, the duration of secondary creep in CSR tests is also assumed to be zero (points $m$ in Figs. 1 and 4 and Fig. 13).

When time $t=t_{\mathrm{m}}, \tau=1$, and $f(1)=0$, then regardless of the material type, strain rate, or temperature eq 45 yields the failure criteria:

$$
\bar{\sigma}=1 \text { and } \bar{\epsilon}=1
$$

equivalent to eq 4 . The normalized stress-strain curve constructed according to eq 45 is shown in Figure 1.

\section{Secant modulus}

The stress-strain relationship for CSR tests can also be expressed in the terms of a secant modulus (Fig. 14):

$$
\sigma=\epsilon E(\tau)
$$

where

$$
E(\bar{\epsilon})=E(\tau)=\frac{\sigma_{\max }}{\epsilon} e^{-\delta \mathrm{f}(\tau) / \mathrm{m}}
$$

is the secant modulus. At the moment of failure, $\sigma=\sigma_{\max }, \epsilon=\epsilon_{\mathrm{m}}$, and $E(\tau)=E_{\mathrm{m}}$, i.e.

$$
\sigma_{\max }=\epsilon_{\mathrm{m}} E_{\mathrm{m}}
$$

Combining eqs 49 and 50, one obtains

$$
E(\tau)=\frac{E_{\mathrm{m}}}{\tau} e^{-\delta \mathrm{f}(\tau) / \mathrm{m}}
$$

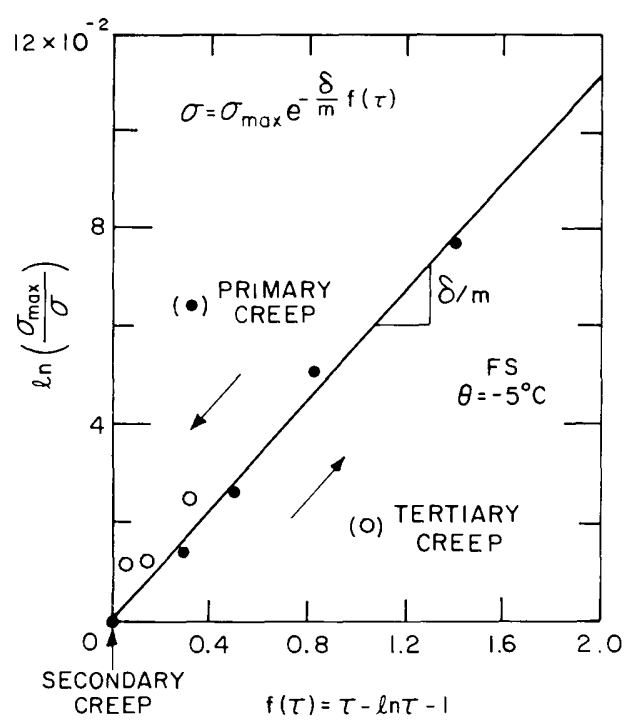

Figure 13. Determination of ratio $\delta / \mathrm{m}$.

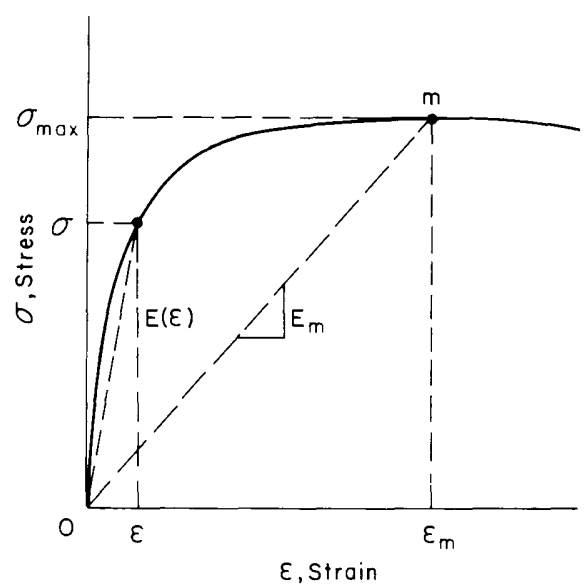

Figure 14. Diagram for calculation of secant modulus. $\mathrm{E}_{\mathrm{m}}$ is the secant modulus at failure.

Note that eq 51 is nonlinear, similar to the modulus of the nonlinear theory of elasticity. The magnitude of the secant modulus $E(\tau)$ approaches infinity when $\tau \rightarrow 0$ or $\epsilon \rightarrow 0$. For solutions of boundary problems, however, such a deficiency of the model is insignificant.

\section{Stress/strain/strain rate at failure}

The relationship between stress, strain, and the applied strain rate at failure when $t=t_{\mathrm{m}}, \tau=1$, and $\epsilon=\epsilon_{\mathrm{m}}$ for two consecutive tests is, according to eq 41 , described by

$$
\sigma_{\max _{1}}=\sigma_{\max _{2}}\left(\frac{\dot{\epsilon}_{1} \epsilon_{\mathrm{m}_{2}}}{\dot{\epsilon}_{2} \epsilon_{\mathrm{m}_{1}}}\right)^{\frac{1}{\mathrm{~m}}}
$$

where $\sigma_{\max _{1}}$ and $\epsilon_{\mathrm{m}_{1}}$ are the peak (maximum) stress and its corresponding strain, respectively, obtained at strain rate $\dot{\epsilon}_{1}$; and $\sigma_{\max _{2}}$ and $\epsilon_{\mathrm{m}_{2}}$ are the peak (maximum) stress and its corresponding strain, respectively, obtained at strain rate $\dot{\epsilon}_{2}$.

If $\epsilon_{\mathrm{m}_{1}}=\epsilon_{\mathrm{m}_{2}}=$ Const., eq 52 is simplified:

$$
\sigma_{\max _{1}}=\sigma_{\max _{2}}\left(\frac{\dot{\epsilon}_{1}}{\dot{\epsilon}_{2}}\right)^{\frac{1}{\mathrm{~m}}} .
$$

Equation 53 is in agreement with a known empirical relationship widely used in describing creep in metals (Nadai 1950, Rabotnov 1966).

\section{TEST DATA}

The results of short-term, unconfined compression 
creep tests performed by Zhu and Carbee (1983a,b) on Fairbanks silt (FS) at constant stress and at constant strain rates are presented in Figures 2,3 , and 4 and Tables 1 and 2 . The tests were conducted at $-5^{\circ} \mathrm{C}$ using remolded soil specimens with a dry density of from 1.16 to $1.24 \mathrm{~g} / \mathrm{cm}^{3}$ and a water content from $40 \%$ to $44.8 \%$, respectively. The specimens were vacuum-saturated and quick-frozen in an open system. The CS creep tests were carried out using a test apparatus developed by Sayles (1968). The CSR tests were performed on a universal loading machine.

\section{Preliminary analysis}

The unity of the deformation and failure processes under two different loading regimes - constant stress and constant strain rate - will now be demonstrated.

\section{Time-dependent failure}

For the CS creep tests, the dependency shown in Figure 5 is based upon the test data presented in Figure 2 and Table 1 . The times to failure $t_{\mathrm{m}}$ for the corresponding stresses $\sigma$ were determined at points $m$ where the strain rates are the minima $\dot{\epsilon}_{\mathrm{m}}$. In the normalized time to failure $\tau_{\mathrm{o}}, t_{\mathrm{o}}=2.7 \times 10^{-2} \mathrm{~s}$ (see Constant stress tests below). The stress ratios $\left(\sigma / \sigma_{0}\right)$ were calculated assuming that the highest stress in the CSR test is the instantaneous strength $\sigma_{\mathrm{o}}=121.2 \mathrm{~kg} / \mathrm{cm}^{2}$ (Table 2 ).
For CSR tests (Fig. 4 ), the stress ratios $\left(\sigma_{\max } / \sigma_{\mathrm{o}}\right)$ were calculated using the same stress $\sigma_{0}=121.2 \mathrm{~kg} / \mathrm{cm}^{2}$. The times to failure $t_{\mathrm{m}}$ presented in Table 2 were determined by eq 39 , using the strains $\epsilon_{\mathrm{m}}$ and strain rates $\dot{\epsilon}$ that correspond to the peak stresses $\left(\sigma_{\max }\right)$; parameter $t_{\mathrm{o}}=2.7 \times 10^{-2} \mathrm{~s}$ was calculated by eq 6 (see Constant strain rate tests below).

In Figure 5 the experimental points for both loading regimes are superposed on one curve, indicating that in both cases time-dependent failure can be described by a unified failure criterion. A similar relationship between the two loading regimes for poly. crystalline ice was shown by Mellor and Cole (1983).

\section{Rheological curve}

In the classical sense, the rheological curve is the relationship between the secondary creep strain rate and applied stress, presented on logarithmic coordinates. It is more convenient, however, to present the test data according to eqs 10 and $44 \mathrm{a}$, as a dependency between the minimum strain rate $\dot{\epsilon}_{\mathrm{m}}$ and the stress ratio $\left(\sigma / \sigma_{0}\right)$ for CS tests, and as a dependency between the applied strain rate $\left(\dot{\epsilon}=\dot{\epsilon}_{\mathrm{m}}\right)$ and the stress ratio $\left(\sigma_{\max } / \sigma_{o}\right)$ for CSR tests. The same instantaneous strength $\left(\sigma_{\mathrm{o}}=121.2 \mathrm{~kg} / \mathrm{cm}^{2}\right)$ was used to calculate both stress ratios.

The rheological curve for both loading regimes is presented in Figure 7. The experimental points for

Table 1. Constant stress tests ( $\sigma=$ Const. $)$. Data from $Z$ hu and Carbee (1983a).

\begin{tabular}{|c|c|c|c|c|}
\hline $\begin{array}{c}\sigma \\
\left(\mathrm{kg} / \mathrm{cm}^{2}\right)\end{array}$ & $\begin{array}{c}\dot{\epsilon}_{m} \\
\left(s^{-1}\right)\end{array}$ & $\begin{array}{c}\epsilon_{m}^{c} \\
(\%)\end{array}$ & $\begin{array}{c}t_{m} \\
(\min )\end{array}$ & Comments \\
\hline 40 & $6.05 \times 10^{-4}$ & 8.9 & 2 & \\
\hline 30 & $1.31 \times 10^{-4}$ & 9.8 & 9.8 & \\
\hline 23.6 & $3.67 \times 10^{-5}$ & 10.6 & 34 & \\
\hline 20 & $7.34 \times 10^{-6}$ & 9.2 & 180 & $\begin{array}{l}\text { Possible slight variations of } \\
\text { temperature during this test }\end{array}$ \\
\hline
\end{tabular}

Table 2. Constant strain rate tests $(\dot{\epsilon}=$ Const. $)$. Data from $\mathrm{Zhu}$ and Carbee (1983b).

\begin{tabular}{|c|c|c|c|c|}
\hline$\left(\begin{array}{c}\dot{\epsilon} \\
\left(s^{-1}\right)\end{array}\right.$ & $\begin{array}{c}\sigma_{\max } \\
\left(\mathrm{kg} / \mathrm{cm}^{2}\right)\end{array}$ & $\begin{array}{l}\epsilon_{m} \\
(\%) \\
\end{array}$ & $\begin{array}{c}t_{m} \\
(\min ) \\
\end{array}$ & Comments \\
\hline $6.5 \times 10^{-2}$ & 121.2 & 1.7 & $4.3 \times 10^{-3}$ & $\begin{array}{l}\text { Instantaneous strain rate and } \\
\text { strength }\left(\sigma_{\text {max }}=\sigma_{0}, \dot{\epsilon}=\dot{\epsilon}_{\mathrm{O}}\right)\end{array}$ \\
\hline $1.1 \times 10^{-3}$ & 41.8 & 9 & 1.4 & \\
\hline $1.1 \times 10^{-4}$ & 25.8 & 10 & 15.2 & \\
\hline $1.1 \times 10^{-5}$ & 20.5 & 8 & 121.2 & \\
\hline $1.1 \times 10^{-6}$ & 17.5 & 5 & 757.6 & \\
\hline
\end{tabular}


both loading regimes are superposed on one curve, indicating that in both cases the flow of soil at secondary creep can be described by a unified flow equation. A similar conclusion was reached by Mellor and Cole (1983) based on test data on the creep of polycrystalline ice.

\section{Normalized strain rates and stress ratios vs normalized time}

Fish $(1976,1979,1980)$ introduced this creep model, including the concepts of normalized time $\left(t / t_{\mathrm{m}}\right)$, normalized stress ratios $\left(\sigma / \sigma_{\mathrm{o}}\right)$, and consequently normalized strain rates $\left(\dot{\epsilon} / \dot{\epsilon}_{\mathrm{m}}\right)$, because the conventional plot ( $\log \dot{\epsilon}$ vs $\log t$ ) shown in Figure 3 and the conventional rheological curve ( $\log \dot{\epsilon}_{\mathrm{m}}$ vs $\log \sigma$ ), which are usually used to derive creep models, were inadequate.

Indeed, we cannot take the logarithm of a quantity that has dimensions. When we do deliberately, to emphasize the differences between particular tests, we always assume that the values of the strain rates and the time have denominators (referenced parameters) that render the strain rates and the times dimensionless. In the case of creep, however, these referenced parameters become functions of stress and temperature, and instead of a single plot $(\log \dot{\epsilon}$ vs $\log t)$ on which all the test results would be superposed regardless of stress and temperature, we obtain a separate family of curves for each temperature.

It has always been known that it is virtually impossible to derive empirically a constitutive equation for a creep model or to select an empirical formula that corresponds to the test data with parameters that are independent of stress and temperature. Every creep curve, even for a given stress and temperature, has at least a slightly different shape due to variations in the properties of the soil specimen. The use of normalized concepts together with the Rate Process Theory makes it possible to smooth out differences in the specific behaviors of specimens and to derive constitutive equations with temperature-independent parameters.

The normalized strain rates, stress ratios, and times presented in this paper have a definite physical sense: they reflect the change of the entropy of the creep process.

It is precisely the entropy increments $\Delta S$ and $\Delta S^{*}$ that unify the two loading regimes. To prove the validity of this statement, the test data in Figures 2 and 3 must be superposed on the test data in Figure 4.

The relationship ( $\log \dot{\epsilon}$ vs $\log t$ ) obtained in the CS tests presented in Figure 3 can be replotted on semilogarithmic coordinates ( $\log \dot{\epsilon}$ vs $\tau$ ), as shown in Figure 9 . Then the ordinates of the curves are expressed in terms of a normalized strain rate $\left(\dot{\xi}=\dot{\epsilon} / \dot{\epsilon}_{\mathrm{m}}\right)$, dividing the strain rates $\dot{\epsilon}$ by the corresponding minimum strain rates $\dot{\epsilon}_{\mathrm{m}}$. This plot is shown in Figure 10. We can see that the experimental points form a curve that can be described by a single constitutive equation. According to eqs 2 and 24 , function $\dot{\xi}(\tau)$ indicates the change of entropy increment $\Delta S(\tau)$ with normalized time.

The relationship of the stress ratio $\left(\sigma_{\text {max }} / \sigma\right)^{\mathrm{m}}$ vs the normalized time $\tau$ for $m=7$, based upon data obtained from CSR tests, is shown in Figure 11. In this plot the experimental points also form a curve that can be described by a single constitutive equation. According to eq 47 , the change of the function $(1 / \bar{\sigma})^{\mathrm{m}}=\left(\sigma_{\max } / \sigma\right)^{\mathrm{m}}$ with time $(\tau)$ reflects the change of the entropy increment $\Delta S(\tau)$ with normalized time.

Figures 10 and 11 are drawn to the same scale, so that the plots for the two loading regimes can be superposed. In Figure 11 the CS test data at $\sigma=20$ $\mathrm{kg} / \mathrm{cm}^{2}$ is superposed on the CSR test data. Note that in both cases the curves have minima when time $\tau=1$, confirming the validity of the failure criterion eq 4 .

\section{Constant stress tests $(\sigma=$ Const. $)$}

\section{Parameters $m$ and $t_{\mathrm{o}}(E)$}

To determine parameters $m$ and $t_{\mathrm{o}}$ according to eq 5 , the test data on time-dependent failure in Table 1 are presented on the coordinates shown in Figure 6:

$$
T \ln \left(\frac{t_{\mathrm{m}} k T}{h}\right)=\frac{E}{R}+m T \ln \left(\frac{\sigma_{\mathrm{o}}}{\sigma}\right) .
$$

The slope of the straight line gives $m \approx 7$. The intersect with the ordinate is equal to the ratio $E / R \approx$ $6.9 \times 10^{3}(\mathrm{~K})$, which gives the value of the activation energy $E \approx 13.8 \mathrm{kcal} / \mathrm{mole}$. Time to failure $t_{\mathrm{m}}$ in this calculation is in seconds and $T=268.16^{\circ} \mathrm{K}$. Parameter $t_{\mathrm{o}}=2.7 \times 10^{-2} \mathrm{~s}$, calculated by eq 6 , is smaller than time $t_{\mathrm{m}}$ for $\sigma_{\mathrm{o}}$ obtained in the CSR tests (Table 2).

The absolute values of $t_{\mathrm{o}}$ and $m$ are closely interconnected. In the case of unfrozen soils, or if the temperature of the frozen soil is constant, $t_{\mathrm{o}}$ and $m$ may be determined directly by plotting the test data with eq $5 b$ :

$$
\ln t_{\mathrm{m}}=\ln t_{\mathrm{o}}+m \ln \left(\frac{\sigma_{\mathrm{o}}}{\sigma}\right)
$$

or they may be calculated with eq $5 \mathrm{c}$ :

$$
\ln \left(\frac{t_{\mathrm{m}}}{t_{\mathrm{o}}}\right)=m \ln \left(\frac{\sigma_{\mathrm{o}}}{\sigma}\right)
$$

in which $t_{\mathrm{o}}$ corresponds to time to failure $t_{\mathrm{m}}$ for stress $\sigma_{\mathrm{o}}($ Table 2$)$. 
Note that $t_{\mathrm{o}}$ and $m$ depend substantially upon temperature. For instance, calculated by eq $5 b, m$ ranges from approximately 3 to 13 if the temperature of the frozen soil changes from $-1^{\circ} \mathrm{C}$ to $-10^{\circ} \mathrm{C}$. The magnitudes of $t_{\mathrm{o}}$ also vary within wide limits. Determination of $t_{o}$ and $m$ by means of eq 5 a gives more stable values for these parameters.

Parameters $\delta$ and $\psi_{\mathrm{m}}$

According to eq 23 , the magnitude of $\delta$ is determined by plotting the normalized strain rate $\left(\dot{\epsilon} / \dot{\epsilon}_{m}\right)$ vs the function $f(\tau)$ on semilogarithmic coordinates. This plot is shown in Figure 12 for the creep curve at $\sigma=20 \mathrm{~kg} / \mathrm{cm}^{2}$ for which the slope of $\delta=0.39$. For comparison with the CSR tests, the data from only one CS creep curve and one CSR curve were plotted in Figure 12. It can be shown, however, that the entire family of creep curves plotted in this manner also forms a straight line. In this case, however, the slope $\delta$ may be slightly different.

The integration coefficient $\psi_{\mathrm{m}}=1.295$ was calcu. lated by eq 32 . $\psi_{\mathrm{m}}$ and $\delta$ can also be determined from eqs 30 and $32 \mathrm{a}$ using test data (Table 1 ).

\section{Parameters $\tilde{C}$ and $(n+m)$}

The values of parameter $\tilde{C}$ are calculated by eq 36 using the strains $\epsilon_{\mathrm{m}}^{\mathrm{c}}$ given in Table 1. Thus, for the test at $\sigma=20 \mathrm{~kg} / \mathrm{cm}^{2}, \epsilon_{\mathrm{m}}^{\mathrm{c}}=9.2 \%, \psi_{\mathrm{m}}=1.295$, and $\tilde{C}=0.071$.

The sum of $(n+m)$ is determined according to eq 10 by plotting the test data in Table 1 on the coordinates, as shown in Figure 8:

$$
T \ln \left(\frac{\tilde{C} k T}{\dot{\epsilon}_{\mathrm{m}} h}\right)=\frac{E}{R}+(n+m) T \ln \left(\frac{\sigma_{\mathrm{o}}}{\sigma}\right) .
$$

The intersect with the ordinate is equal to the ratio $E / R \approx 6.9 \times 10^{3}\left({ }^{\circ} \mathrm{K}\right)$. The slope of the straight line is equal to $(n+m) \approx 6.8$, which approximately equals the magnitude of $m \approx 7$ obtained above. Thus, since by definition parameter $n \geqslant 0$ (eq 1 ), we can conclude that for these tests $n=0$.

For unfrozen soils, or if the temperature of the frozen soil is constant, $\tilde{C}$ and the sum $(n+m)$ may be determined directly by plotting the test data with eq 11a:

$$
\ln \left(\dot{\epsilon}_{\mathrm{m}} t_{\mathrm{o}}\right)=\ln \tilde{C}+(n+m) \ln \left(\frac{\sigma}{\sigma_{\mathrm{o}}}\right)
$$

where $t_{\mathrm{o}}$ corresponds to time to failure $t_{\mathrm{m}}$ of the instantaneous strength $\sigma_{o}$. As in the case of timedependent failure, however, $t_{0}$ and $(n+m)$ can be very sensitive to temperature change.

In previous publications (Fish 1982a,b; 1983a), other methods for determining parameters $\delta, m, n$, and $t_{\mathrm{o}}(E)$ have been discussed.

\section{Constant strain rate tests $(\dot{\epsilon}=$ Const. $)$}

Parameters $m$ and $t_{\mathrm{o}}(E)$

Since the equation for time-dependent failure at constant strain rates (eq 44) is identical to that for creep tests (eq 5 ), the method for determining parameters $m, t_{\mathrm{o}}$, and $E$ is analogous to that for creep tests. Thus, in Figure 6 the test data presented in Table 2 are plotted in accordance with eq 44 :

$$
T \ln \left(\frac{\epsilon_{\mathrm{m}} k T}{\dot{\epsilon} h}\right)=\frac{E}{R}+m T \ln \left(\frac{\sigma_{\mathrm{o}}}{\sigma_{\max }}\right) .
$$

In Figure 6, we see that the CSR test data are superposed on the same straight line as the CS creep test data. Therefore, the values of parameters $m, t_{0}$, and $E$ will also be the same.

For unfrozen and in some cases frozen soils, as shown above, the determination of $m$ and $t_{\mathrm{o}}$ may be simplified, using eq $11 \mathrm{a}$ in which $\sigma=\sigma_{\max }, n=0$, and $\tilde{C}=\epsilon_{\mathrm{m}}$.

\section{Parameters $\delta$ and $\tilde{C}$}

According to eq 47, when $m$ is known, the CSR test curves can be superposed on the CS creep curves. This is shown in Figure 12 for two tests: at $\sigma=20$ $\mathrm{kg} / \mathrm{cm}^{2}$ and at $\dot{\epsilon}=1.1 \times 10^{-5} \mathrm{~s}^{-1}$. The value of $\delta \mathrm{re}-$ mains unchanged. From eq 46 it follows that parameter $\delta$ can also be obtained by plotting the stress ratios $\left(\sigma_{\max } / \sigma\right)$ versus the corresponding values of function $f(\tau)$ on semilogarithmic coordinates, as in Figure 13. In this case the slope of the straight line is equal to $\delta / m=5.5 \times 10^{-2}$, which gives $\delta=0.385$ for $m=7$.

Parameter $\tilde{C}$ in the CSR test is by definition (eq 42) equal to the failure strain $\epsilon_{\mathrm{m}}$ given in Table 2.

\section{THE PRINCIPLE OF SUPERPOSITION}

We can now formulate the Principle of Superposition of CS and CSR tests:

Creep curves at constant stresses and stressstrain curves at constant strain rates can be superposed if the test data are presented as functions of the change of entropy over normalized time.

This principle can be expressed in terms of normalized strain rates and normalized stress ratios, combining eqs 22, 24, and 47: 


$$
\frac{\dot{\epsilon}}{\dot{\epsilon}_{\mathrm{m}}}=\left(\frac{\sigma_{\max }}{\sigma}\right)^{\mathrm{m}}
$$

where the left and right sides of eq 54 refer to the data obtained from CS and CSR tests, respectively.

The Principle of Superposition can be extended to the area of creep deformation and the stress-strain relationship. Thus, in Figure 15 the creep curves from Figure 2 are superposed on the curve calculated by eq 37 using $\delta=0.39$ and $\psi_{\mathrm{m}}=1.295$. In Figure 16 the stress-strain curves from Figure 4 are superposed on the curve calculated by eq 45 using $\delta=0.39$ and $m=7$.

The creep model can be considered valid if the families of both the creep and the stress-strain curves (Figs. 2 and 4) can be superposed at all stages of
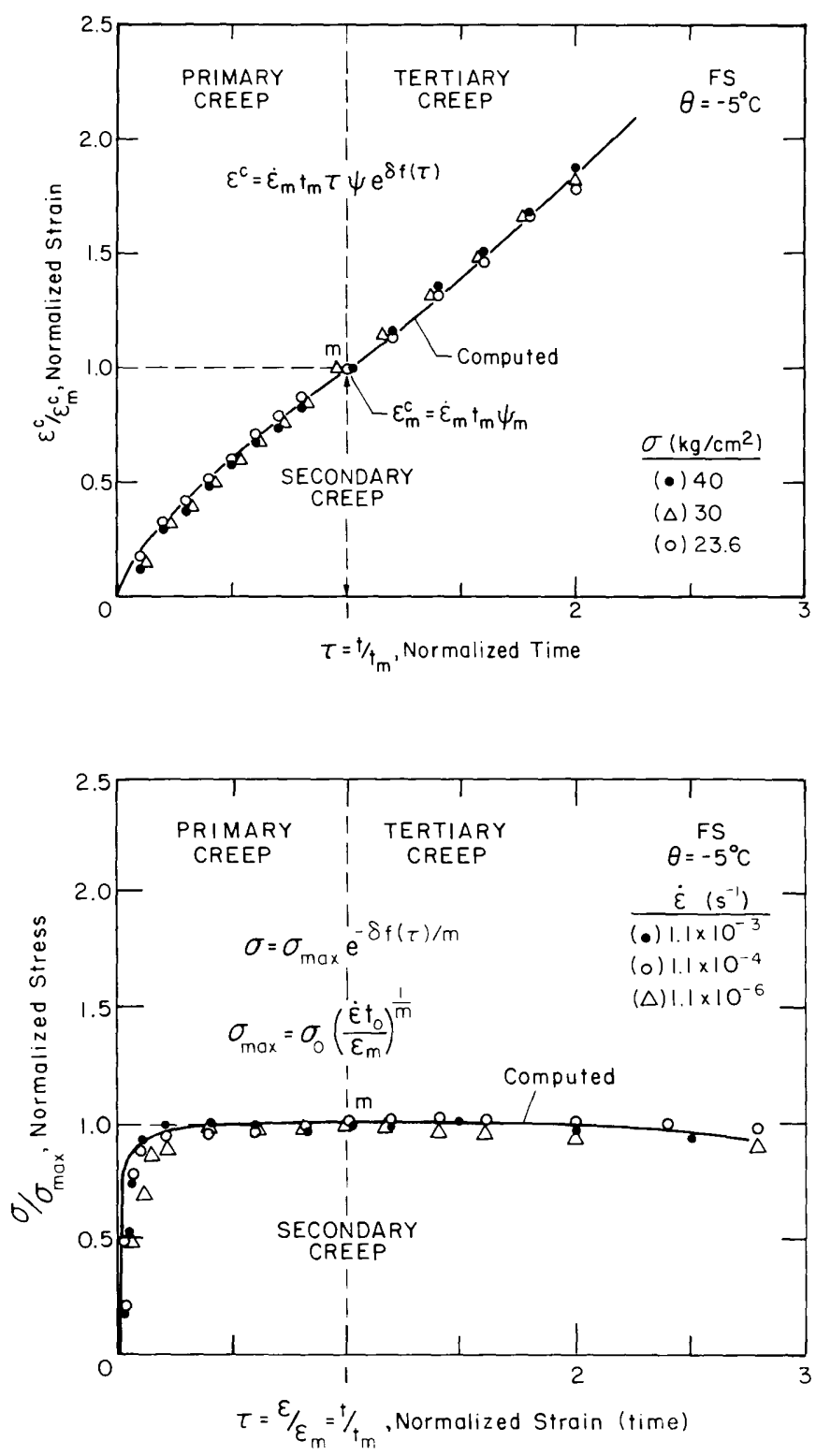

creep - primary, secondary, and tertiary. In Figure 17, the $\epsilon^{\mathrm{c}}$ and $\epsilon_{\mathrm{m}}^{\mathrm{c}}$ test data from Figure 15 and the $\left(\sigma_{\max } / \sigma\right)^{\mathrm{m}}$ test data from Figure $16(m=7)$ are replotted on the coordinates:

Creep at constant stress ( $\sigma=$ Const.)

$$
Y=\frac{\epsilon^{\mathrm{c}} \psi \mathrm{m}}{\epsilon_{\mathrm{m}}^{\mathrm{c}} \psi} e^{-\delta \mathrm{f}(\tau)}=\tau .
$$

Creep at constant strain rate $(\dot{\epsilon}=$ Const. $)$

$$
Y^{\prime}=\left(\frac{\sigma_{\max }}{\sigma}\right)^{\mathrm{m}} \tau e^{-\delta \mathbf{f}(\tau)}=\tau
$$

In both cases the test data form straight lines at angles of $45^{\circ}$ to the axis of the normalized time.

Figure 15. Normalized creep curve.

Figure 16. Normalized stress-strain curve. 


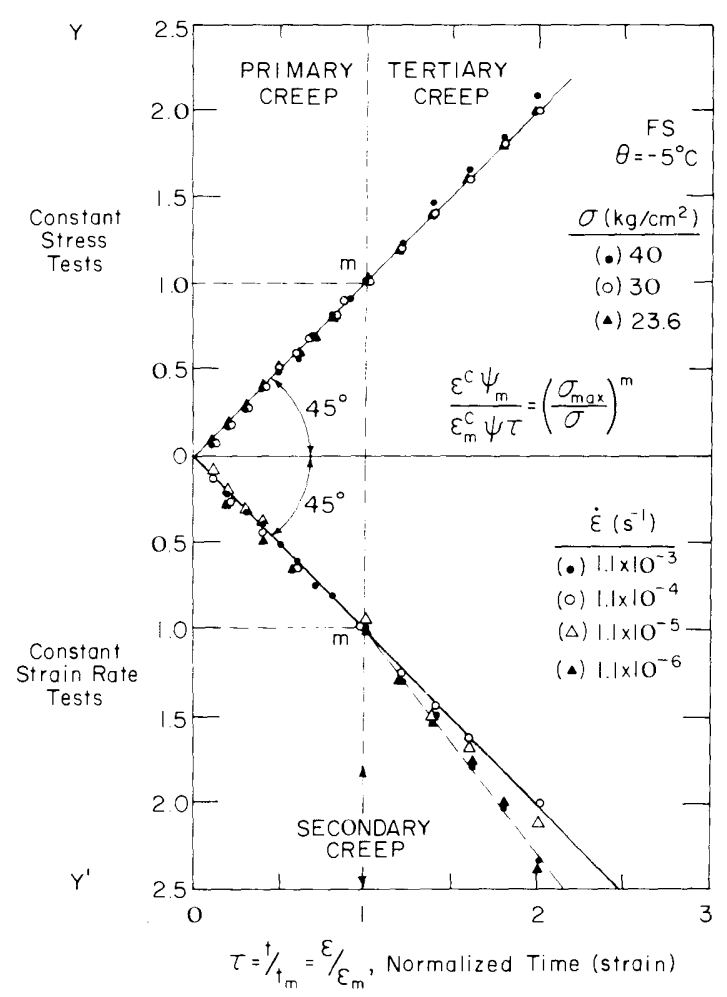

Figure 17. Superposition of creep (CS) and constant strain rate (CSR) tests.

Combining eqs 37a and 47a, we can write the Principle of Superposition for creep strain in analytical form:

$$
\frac{\epsilon^{\mathrm{c}} \psi_{\mathrm{m}}}{\epsilon_{\mathrm{m}}^{\mathrm{c}} \psi \tau}=\left(\frac{\sigma_{\max }}{\sigma}\right)^{\mathrm{m}} .
$$

The CS and CSR test data are in fact superposed in Figure 17, confirming the validity of the model. The slight diversion at the ends of the tertiary creep stages can be attributed to changes in the properties of the soil specimens and to the change of the failure mechanism at this stage.

\section{THERMODYNAMIC EQUATION OF CREEP}

It has been shown that deformation and failure in CS and CSR tests are, in fact, a unified thermoactivated process in which the dominant role belongs to the change of entropy. Thus, combining eqs 1,2 , 9 , and $9 \mathrm{a}$, and assuming that $n=0$, we obtain a thermodynamic equation of creep for both CS and CSR loading regimes:

$$
\dot{\epsilon}=\tilde{C} \frac{k T}{h} \exp \left(-\frac{E}{R T}\right) \exp \left(\frac{\Delta S-\Delta S^{*}}{k}\right) .
$$

Note that both entropy increments $\Delta S$ and $\Delta \stackrel{*}{S}$ are functions of stress and temperature. They are closely interconnected, and their relationship predetermines the direction of the creep process:

- If stress $\sigma=$ Const., then $\Delta S=$ Const. and, since $\Delta S=f(\tau)$, the strain rate is also a function of time (eq 19).

- If strain rate $\dot{\epsilon}=$ Const. and $\Delta S=f(\tau)$, then the entropy increment and the stress in eq 9a both become functions of time:

$$
\frac{\Delta S^{*}(\tau)}{k}=m \ln \left(\frac{\sigma_{0}}{\sigma(\tau)}\right),
$$

as described by eqs 43 and 47 .

- If $\Delta S=0$ (secondary creep) and the minimum strain rates in CS tests are equal to the strain rates in CSR tests $\left(\dot{\epsilon}_{\mathrm{m}}=\dot{\epsilon}\right)$, then the entropy increments $\Delta \stackrel{*}{S}$ in both CS and CSR tests are equal as well, and so are the stresses $\sigma=\sigma_{\max }$. The reverse is also true, i.e.

$$
\dot{\epsilon}_{\mathrm{m}}=\dot{\epsilon} \quad \text { and } \quad \sigma=\sigma_{\max } .
$$

- If strain rate $\dot{\epsilon}=\dot{\epsilon}_{o}=$ Const. and $\Delta S=f(\tau)$, then stress is also a function of time, $\sigma=f(\tau)$. At secondary creep when $\Delta S=0$, the stress becomes $\sigma_{\max }=\sigma_{\mathrm{o}}$. (It is assumed that this case is not applicable for CS tests where $\sigma<\sigma_{0}$.)

- If $\Delta S=\Delta S$, the strain rate becomes (Fish 1976a, 1980)

$$
\dot{\epsilon}_{\mathrm{o}}=\tilde{C} \frac{k T}{h} \exp \left(-\frac{E}{R T}\right)=\frac{\tilde{C}}{t_{\mathrm{o}}},
$$

and when $\Delta S=\Delta \stackrel{*}{S}=0$, the corresponding peak (maximum) stress is, as defined, the instantaneous strength $\sigma_{0}$.

The creep process for both CS and CSR tests can be expressed in terms of the free energy $\tilde{E}$ of the thermal activation. Thus, we can substitute Boltzmann's constant $k$ in eq 56 for the gas constant $R=k N$, where $N$ is Avogadro's number, and $\Delta \mathbf{S}=$ $\Delta S N, \Delta \overrightarrow{\mathrm{S}}=\Delta \stackrel{*}{S} N$, and

$$
\tilde{E}=E-\Delta \mathbf{S} T+\Delta \stackrel{*}{\mathbf{S}} T .
$$

If $\Delta \mathbf{S}=0$ and $\sigma=\sigma_{\max }$ (secondary creep),

$$
\tilde{E}=E+\Delta \stackrel{*}{\mathbf{S}} T=E+R T \ln \tau_{\mathrm{o}} .
$$


When $\Delta \stackrel{*}{\mathbf{S}}=0$ and $\sigma=\sigma_{\max }=\sigma_{o}$ (primary and tertiary creep),

$$
\tilde{E}=E-\Delta \mathbf{S} T=E-R T \delta f(\tau) .
$$

Combining eqs 56 and 59, the thermodynamic equation of creep transforms into the Eyring-Frenkel (Rate Process Theory) kinetic equation:

$$
\dot{\epsilon}=\tilde{C} \frac{k T}{h} e^{-\tilde{\mathrm{E}} / \mathrm{RT}}
$$

in which the free energy $\tilde{E}$ and consequently the strain rate $\dot{\epsilon}$ can be calculated using only three parameters, $\tilde{C}, E$, and $\delta$. The methods for determining these parameters from CS and CSR tests have been discussed above.

Since $\Delta S$ and $\Delta \stackrel{*}{S}$ are temperature-dependent and $\Delta S$ (and $\Delta \stackrel{*}{S}$ in CSR tests as well) is a function of time, the apparent activation energy $\tilde{E}$ becomes a function of stress, time, and temperature (Tietz and Dorn 1956; Zhurkov and Sanfirova 1958; Andersland and Akili 1967; Mitchell et al. 1968; Andersland and AlNouri 1970; Regel et al. 1974; Vialov 1978; and others).

\section{CONCLUSIONS}

A unified creep model has been developed, which for the first time describes the entire creep process including primary, secondary, and tertiary creep and failure for both constant stress (CS) tests and constant strain rate (CSR) tests.

- Deformation and failure are considered as a single thermoactivated process and are described by a unified thermodynamic equation of state. The activation energy was found to be a material constant independent of the loading regime.

- The dominant role in the processes of deformation and failure belongs to the change of entropy: failure occurs when the entropy change is zero.

- The stress-strain state of the material with no changes of entropy is characterized by the minimum values of the strain rates in CS tests and the maximum (peak) values of stress in CSR tests.

The Principle of Superposition has been formulated, according to which creep ( $\epsilon$ vs $t$ ) curves and stress-strain ( $\sigma \vee v \in$ ) curves can be superposed if the data from CS and CSR tests are presented as functions of the change of entropy over normalized time.
A method has been developed to determine the parameters of the model so that creep deformation and the stress-strain relationship of a ductile material such as soil can be predicted using information from either type of test.

\section{LITERATURE CITED}

Andersland, O.B., and W. Akili (1967) Stress effect on creep rates of a frozen clay soil. Geotechnique, 17(1): 27-39.

Andersland, O.B. and I. AlNouri (1970) Time-dependent strength behavior of frozen soils. Journal of the Soil Mechanics and Foundations Division, Proceedings of the American Society of Civil Engineers, 96(SM4): 1249-1265.

Audersland, O.B., F.H. Sayles, Jr., and B. Ladanyi (1978) Mechanical properties of frozen ground. In Geotechnical Engineering for Cold Regions (O.B. Andersland and D.M. Anderson, Eds.). New York: McGraw-Hill, pp. 216-275.

Assur, A. (1980) Some promising trends in ice mechanics. In Physics and Mechanics of Ice (P. Tryde, Ed.). Proceedings of the IUTAM Symposium. Copenhagen: Springer-Verlag, pp. 1-15.

Bragg, R.A., and O.B. Andersland (1980) Strain rate, temperature and sample size effects on compression and tensile properties of frozen sand. In Proceedings of the Second International Symposium on Ground Freezing, Trondheim, Norway, pp. 34-47.

Fish, A.M. (1976a) An acoustic and pressure meter method for investigation of the rheological properties of ice. Cand. Sci. thesis, Arctic and Antarctic Research Institute, Leningrad, U.S.S.R. (translated from Russian, 1978). Hanover, New Hampshire: USA Cold Regions Research and Engineering Laboratory Internal Report 846, 205 pp. Fish, A.M. (1976b). An acoustic method for prediction of strength of structures. In Construction Structures, Construction Physics (in Russian). Izd-vo TSINIIS, Series VIII, 10. Moscow, pp. 53-56. Fish, A.M. (1979) Mechanical properties of frozen soils. Research Proposal. Con tract No. DAAG 2977C-0016 Part B. Cambridge: Massachusetts Institute of Technology, pp. B1-B5.

Fish, A.M. (1980) Kinetic nature of the long-term strength of frozen soils. In Proceedings of the Second International Symposium on Ground Freezing, Trondheim, Norway, pp. 95-108.

Fish, A.M. (1982a) Comparative analysis of the U.S. S.R. construction codes and the U.S. Army technical manual for design of foundations on permafrost. USA Cold Regions Research and Engineering Laboratory CRREL Report 82-14, ADA1 16234. 
Fish, A.M. (1982b) Deformation and failure of frozen soils and ice at constant and steadily increasing stresses. In Proceedings of the Fourth Canadian Permafrost Conference, 4-6 March 1981, Calgary, Alberta (Roger J.E. Brown memorial volume, H.M. French, Ed.). Ottawa: National Research Council of Canada, pp. 419-428.

Fish, A.M. (1983a) Comparison of U.S.S.R. codes and U.S. Army manual for design of foundations on permafrost. Cold Regions Science and Technology, 8(1): 3-24.

Fish, A.M. (1983b) Creep deformation, failure, and acoustic emission: A unified kinetic process. Cold Regions Science and Technology (in press).

Fish, A.M. and F.H. Sayles (1981) Acoustic emissions during creep of frozen soils: Acoustic emission in geotechnical engineering practice (V.P. Drnevich and R.E. Gray, Eds.). American Society for Testing and Materials Special Technical Publication No. 750, pp. 194-206.

Fish, A.M. and A. Assur (1983) Discussion paper, Tertiary creep model for frozen sand, by J.M. Ting. ASCE Journal of Geotechnical Engineering (in press). Frenkel, J.I. (1947) Kinetic Theory of Liquids. Oxford: Clarendon Press, 488 pp.

Garofalo, F. (1965) Fundamentals of Creep and Creep Rupture in Metals. New York: MacMillan Co., 288 pp. Glasstone, S., K.J. Laidler, and H. Eyring (1941) The Theory of Rate Processes. New York: McGraw-Hill, $611 \mathrm{pp}$.

Gold, L.W. (1972a) Activation energy for creep of columnar-grained ice. In Proceedings of the International Conference on Physical Chemistry of Ice. Ottawa: Royal Society of Canada.

Gold, L.W. (1972b) The process of failure of columnargrained ice. Philosophical Magazine, 26: 311-328. Gold, L.W. (1973) Ice-A challenge to the engineer. In Proceedings, Fourth Canadian Congress of Applied Mechanics, Montreal, pp.G19-G36.

Goughnour, R.R. and O.B. Andersland (1968) Mechanical properties of a sand-ice system. Journal of the Soil Mechanics and Foundations Division, Proceedings of the American Society of Civil Engineers, 94 (SM4): 923-950.

Jessberger, H.L. (1980) State-of-the-art report. Ground freezing: Mechanical properties, processes and design. In Proceedings of the Second International Symposium on Ground Freezing, Trondheim, Norway. pp. 1-33.

Ladanyi, B. (1972) An engineering theory of creep of frozen soils. Canadian Geotechnical Journal, 9(1): 63-80.

Mellor, M. and D.M. Cole (1982) Deformation and failure of ice under stress or constant strain-rate. Cold Regions Science and Technology, 5(3): 201-219.
Mellor, M. and D.M. Cole (1983) Stress/strain/time relations for ice under uniaxial compression. Cold Regions Science and Technology, 6(3): 207-230.

Mitchell, J.K. (1976) Fundamentals of Soil Behavior. New York: John Wiley \& Son, 422 pp.

Mitchell, J.K. and R.G. Campanella (1963) Creep studies on saturated clays, Symposium on Laboratory Shear Testing of Soils, ASTM-NRC, Ottawa, Canada. American Society for Testing and Materials Special Technical Publication No. 361.

Mitchell, J.K., R.G. Campanella and A. Singh (1968) Soil creep as a rate process. Journal of the Soil Mechanics and Foundations Division, Proceedings of the American Society of Civil Engineers, 94(SM1): 231253.

Murayama, S. and T. Shibata (1961) Rheological properties of clays. In Proceedings of the Fifth International Congress on Soil Mechanics and Foundation Engineering, Paris. pp. 269-273.

Nadai, A. (1950) Theory of Flow and Fracture of Solids. New York: McGraw-Hill.

Odquist, F.K.G. (1966) Mathematical Theory of Creep and Creep Rupture. Oxford: Clarendon Press, 170 pp.

Rabotnov, Yu.N. (1966) Creep Problems in Structural Members (translated from Russian). Nor th Holland Publishing Company, 1969.

Regel, V.R., A.I. Slutsker, and E.E. Tomashevskiy (1974) Kinetic nature of strength of solids (in Russian). Nauka, Moscow, 560 pp.

Sayles, F.H. and N.V. Epanchin (1966) Rate of strain compression tests on frozen Ottawa sand and ice. USA Cold Regions Research and Engineering Laboratory Technical Note, 54 pp. (unpublished).

Sayles, F.H. (1968) Creep of frozen sands. USA Cold Regions Research and Engineering Laboratory Technical Report 190. ADA680902.

Sayles, F.H. and D. Haynes (1974) Creep of frozen silt and clay. USA Cold Regions Research and Engineering Laboratory Technical Report 252. ADA784088.

Sayles, F.H. (1974) Triaxial constant strain rate tests and triaxial creep tests on frozen Ottawa sand. USA Cold Regions Research and Engineering Laboratory Technical Report 253. ADA785506.

Tietz, T. and J. Dorn (1976) Creep of copper at intermediate temperatures. Transactions, American Institute of Mechanical Engineers, 206: 156.

Vialov, S.S. (1959) Rheological properties and bearing capacity of frozen soils. USA Snow, Ice and Permafrost Research Establishment Translation 74 (1965). ADA481 856.

Vialov, S.S., Iu.K. Zaretskii, R.V. Maximyak, and N.K. Pekarskaya (1973) Kinetics of structural deformation and failure of clays. In Proceedings of the Eighth 
International Conference on Soil Mechanics and Foun-

dation Engineering, Moscow, vol. 1, Part 2, pp. 459-464.

Vialov, S.S. (1978) Rheological fundamentals of soil mechanics (in Russian). Vysshaya Shkola, Moscow, 446 pp.

Vialov, S.S., V.G. Gmoshinskii, S.E. Gorodetskii, V.G. Grigor'eva, Iu.K. Zaretskii, N.K. Pekarskaya, and E.P. Shusherina (1962) Strength and creep of frozen soils and calculations for ice soil retaining structures. USA Snow, Ice and Permafrost Research Establishment Translation 76. ADA484093.

Zaretskii, Iu.K. and S.S. Vialov (1971) Structural mechanics of clayey soils. Soil Mechanics and Foundation Engineering, Moscow. 8(3): 153-160.

Zaretskii, Iu. K., A.M. Fish, V.P. Gavrilo, and A.V. Gusev (1975) Short-term ice creep and microcrack formation kinetics. In Physical Methods of Studying
Snow and Ice (V.V. Bogorodskii, Ed.), pp. 196-203. USA Cold Regions Research and Engineering Laboratory Draft Translation 539, ADA030818.

Zhurkov, S.H. and T.R. Sanfirova (1958) Relation between strength and creep of metals and alloys. Soviet Physics, Technical Physics, 3: 1586-1596.

Zhu Yuanlin and D. Carbee (1983a) Creep behavior of frozen silt under constant uniaxial stress. In Proceedings of the Fourth International Conference on Permafrost, Fairbanks, Alaska, 18-22 July. Washington, D.C.: Polar Research Board, National Academy of Sciences, pp. 1507-1512.

Zhu Yuanlin and D. Carbee (1983b) Creep and strength behavior of frozen silt in uniaxial compression. USA Cold Regions Research and Engineering Laboratory CRREL Report (in preparation). 